\title{
Growth-Stimulatory Effect of Quorum Sensing Signal Molecule N-Acyl-Homoserine Lactone-Producing Multi-Trait Aeromonas spp. on Wheat Genotypes Under Salt Stress
}

\author{
Muhammad Shoib Nawaz', Ayesha Arshad'1, Lubna Rajput ${ }^{1,2}$, Kaneez Fatima ${ }^{1,3}$, \\ Sami Ullah ${ }^{1,4}$, Muhammad Ahmad ${ }^{1}$ and Asma Imran ${ }^{1 *}$ \\ ${ }^{1}$ National Institute for Biotechnology and Genetic Engineering (NIBGE), Faisalabad, Pakistan, ${ }^{2}$ Plant Physiology and \\ Biotechnology Institute, Agriculture Research Centre, Tandojam, Pakistan, ${ }^{3}$ Department of Life Sciences, University \\ of Management and Technology, Lahore, Pakistan, ${ }^{4}$ Department of Botany, Women University of Azad Jammu \& Kashmir, \\ Bagh, Bagh, Pakistan
}

\section{OPEN ACCESS}

Edited by: Samina Mehnaz,

Forman Christian College, Pakistan

Reviewed by:

Anton Hartmann,

Ludwig Maximilian University

of Munich, Germany

Muhammad Farhan UI Haque, University of the Punjab, Pakistan

*Correspondence:

Asma Imran

asmaaslam2001@yahoo.com

Specialty section:

This article was submitted to

Microbiotechnology,

a section of the journal

Frontiers in Microbiology

Received: 19 April 2020

Accepted: 17 August 2020

Published: 29 September 2020

Citation:

Nawaz MS, Arshad A, Rajput L,

Fatima $K$, Ullah S, Ahmad $M$ and Imran A (2020) Growth-Stimulatory

Effect of Quorum Sensing Signal

Molecule N-Acyl-Homoserine

Lactone-Producing Multi-Trait Aeromonas spp. on Wheat

Genotypes Under Salt Stress.

Front. Microbiol. 11:553621. doi: 10.3389/fmicb.2020.553621
Salinity is one of the major threats to agricultural productivity worldwide. Soil and plant management practices, along with inoculation with plant-beneficial bacteria, play a key role in the plant's tolerance toward salinity stress. The present study demonstrates the potential of acyl homoserine lactone (AHL)-producing plant growth promoting rhizobacteria (PGPR) strains of Aeromonas sp., namely, SAL-17 (accession no. HG763857) and SAL-21 (accession no. HG763858), for growth promotion of two wheat genotypes inherently different for salt tolerance potential. AHLs are the bacterial signal molecules that regulate the expression of various genes in bacteria and plants. Both Aeromonas spp., along with innate plant-growth-promoting (PGP) and salt tolerance traits, showed AHL production which was identified on tandem mass spectrometry as C6-HSL, 3-OH-C5-HSL, 3-OH-C6-HSL, 3-oxo-C7-HSL C10-HSL, 3-oxo-C10-HSL, 3-OH-C10-HSL, 3-oxo-C12-HSL and C6-HSL, and 3-oxo-C10-HSL. The exogenous application of purified AHLs (mix) significantly improved various root parameters at $200 \mathrm{mM} \mathrm{NaCl}$ in both salt-sensitive (SSG) and salt-tolerant (STG) genotypes, where the highest increase $(\approx 80 \%)$ was observed where a mixture of both strains of AHLs was used. Confocal microscopic observations and root overlay assay revealed a strong root colonization potential of the two strains under salt stress. The inoculation response of both STG and SSG genotypes was evaluated with two AHL-producing strains (SAL-17 and SAL-21) and compared to non-AHL-producing Aeromonas sp. SAL-12 (accession no. $H G 763856)$ in saline $\left(E C=7.63 \mathrm{~ms} / \mathrm{cm}^{2}\right)$ and non-saline soil. The data reveal that plants inoculated with the bacterial consortium (SAL-21 + SAL-17) showed a maximum increase in leaf proline content, nitrate reductase activity, chlorophyll a/b, stomatal conductance, transpiration rate, root length, shoot length, and grain weight over noninoculated plants grown in saline soil. Both STG and SSG showed relative effectiveness toward inoculation (percent increase for STG: 165-16\%; SSG: 283-14\%) and showed a 
positive correlation of grain yield with proline and nitrate reductase activity. Furthermore, principal component analysis (PCA) and categorical PCA analysis clearly showed an inoculation response in both genotypes, revealing the effectiveness of AHL-producing Aeromonas spp. than the non-AHL-producing strain. The present study documents that the consortium of salt-tolerant AHL-producing Aeromonas spp. is equally effective for sustaining the growth of STG as well as SSG wheat genotypes in saline soil, but biosafety should be fully ensured before field release.

Keywords: AHLs, wheat, Aeromonas, PGPR - plant growth-promoting rhizobacteria, halophilic

\section{INTRODUCTION}

Salinity is edaphic stress that has affected 45 million hectares out of 230 million hectares of irrigated land, causing annual losses of about US\$ 12 billion worldwide (FAO, 2020), and is a major threat to global agricultural productivity. There are two types of salinity: primary salinity which occurs in arid and semi-arid regions due to low average rainfall, excessive weathering of rocks, and improper drainage in soils containing high salt contents (Bui, 2013) and secondary salinity which is mainly caused by human activities such as land clearing, inappropriate irrigation practices, and excessive use of chemical fertilizers (de Wit et al., 2011). Salinity decreases the agricultural production of all major crops and deteriorates the structure and the ecological functioning of the soil. It imposes ion toxicity, osmotic and oxidative stresses, limits water uptake from soil, consequently causing nutrient deficiency, especially phosphorous $(\mathrm{P})$ because $\mathrm{P}$ ions precipitate with Ca ions (Bano and Fatima, 2009). Salinity also affects photosynthetic efficiency, leaf area, stomatal conductance, and chlorophyll contents.

Plants have also co-evolved the adaptation mechanisms (Gupta and Huang, 2014) against salinity. The first phase of plant response to salinity is characterized by the release of phytohormones, mainly abscisic acid (Ismail et al., 2014), the expression of reactive oxygen species (ROS)-scavenging enzymes (Bharti et al., 2013), and the accumulation of osmoprotectants such as proline (Sneha et al., 2013; Iqbal et al., 2014). The exogenous application of nitric oxide (NO) and nitrate reductasemediated NO production are also reported as abiotic stress coping strategy in plants, such that they are involved in the homeostasis of ROS in plants (Sun et al., 2015; Pan Q.-N. et al., 2019). The second phase of plant response is characterized by $\mathrm{Na}^{+}$exclusion from xylem parenchyma cells via plasma membrane porter HKT1 (Lv et al., 2012; Munns et al., 2012), SOS $1 \mathrm{Na}^{+} / \mathrm{H}^{+}$antiporter (Ariga et al., 2013), $\mathrm{Na}^{+}$storage into vacuoles via vacuolar $\mathrm{Na}^{+} / \mathrm{H}^{+}$antiporter (Kronzucker and Britto, 2011), or $\mathrm{Na}^{+}$compartmentalization (Garcia de la Garma et al., 2015).

Many strategies to induce salinity tolerance in plants have been discussed, including genetic engineering of regulatory elements, manipulation of ion transport and transporters, membrane transports, RNAi technology, QTLomics, alternative splicing, and exploring the halobiomes as a gene pool for conferring salt tolerance (Wani et al., 2020). Halobiome is referred to as a group of halophilic and/or halotolerant bacteria, algae, fungi, and plants that can withstand a high-saline environment. It is now generally accepted that plant performance and activities can only be characterized and understood completely if the plant, plus the intimately associated microbiota, is considered. The role of microorganisms in plant growth promotion, nutrient management, and disease control is well established (Naqqash et al., 2020). These microorganisms colonize the rhizosphere/endorhizosphere of plants and promote the growth of plants through various direct and indirect mechanisms (Lugtenberg and Kamilova, 2009; Yang et al., 2009; Upadhyay et al., 2012). The term induced systemic tolerance has been proposed for plant growth promoting rhizobacteria (PGPR)induced physical and chemical changes that result in enhanced tolerance to abiotic stress. Hence, PGPR acts as an effective strategy to mitigate the detrimental effects of stress along with improved plant growth. PGPR inoculation improves nutrient uptake under stress (Dodd and Pérez-Alfocea, 2012; Han et al., 2014), e.g., Pseudomonas sp. inoculation enhances chlorophyll content in maize under salinity while Klebsiella oxytoca inoculation improves nutrient uptake in cotton (Nadeem et al., 2007; Wu et al., 2014). However, the inoculation efficiency is higher under normal conditions compared to the stressed condition because stress not only affects the growth and the physiology of plants but also rhizosphere functioning (Hashem et al., 2015). The rhizosphere is a hotspot for microbial diversity and activity and is affected by various abiotic and biotic factors, including nutrients, $\mathrm{pH}$, moisture, and pathogens (Egamberdieva et al., 2010). Microbes native to saline and hypersaline habitats have well-developed physiological pathways and survival mechanisms to cope with the harsh conditions (Torres et al., 2019) and have shown positive effects on plants under salt stress (Ahmad et al., 2015; Singh and Jha, 2016a; Rajput et al., 2018). Under stress conditions, the plant hormone ethylene endogenously regulates plant homeostasis, which results in reduced root and shoot growth. In the presence of 1-aminocyclopropane-1-carboxylic acid (ACC) deaminaseproducing bacteria, plant ACC is sequestered and degraded by bacterial cells to supply nitrogen and energy. Furthermore, by removing ACC, the bacteria reduce the deleterious effect of ethylene, ameliorating stress and promoting plant growth.

Acyl homoserine lactones (AHLs) are quorum sensing (QS) molecules produced by root-associated bacteria and represent novel elicitors or inducers of biotic and abiotic stress tolerance in plants. They induce rapid changes in the morphology, physiology, and gene expression of roots and shoots (Schikora 
et al., 2016), trigger a collective response to change cell density (Papenfort and Bassler, 2016), produce antifungal/antimicrobial molecules and antibiotics (Chapalain et al., 2013), influence colonization and association with the host, and induce host defense mechanism against pathogens (González and Marketon, 2003). QS-related studies from saline and hypersaline habitats have been mainly reported from family Halomonadaceae (Llamas et al., 2005; Tahrioui et al., 2013) and recently Desulfovibrio vulgaris and Desulfobacterium corrodens (Sivakumar et al., 2019). None of the studies reported on AHL production from PGPR strains isolated from saline and hypersaline rhizosphere.

Aeromonas spp. have been reported as PGPR and/or biocontrol agent from the rhizosphere of different crop plants, including rice (Mehnaz et al., 2001; Sánchez-Matamoros et al., 2018), soybean (Safni and Antastia, 2018), bean and cotton (Inbar and Chet, 1991), chickpea and mustard (Kundu et al., 2009), and wheat (Chibani et al., 2016; Rajput et al., 2018), but AHL-producing PGPR Aeromonas sp. have not been studied until now. AHL-producing Aeromonas hydrophila KOR1 was isolated from mangrove rhizosphere (Yin et al., 2015), Aeromonas caviae strain YL12 was from plant-based compost material (Lim et al., 2014), and Aeromonas sobria was from the spoilage of Scophthalmus maximus L. (Li et al., 2016), but these strains were not characterized as PGPR.

This study was based upon the hypothesis that AHLproducing plant-beneficial bacteria may serve as inducers of salt tolerance in plants with concomitant plant growth promotion. The present study has demonstrated the production of different AHLs, varying in acyl chain length (C5-C12), from halotolerant, plant-beneficial Aeromonas spp. strains isolated from wheat rhizosphere and their subsequent growth-promoting effect on two wheat genotypes (salt tolerant and salt sensitive) under salt stress. Plant inoculation further showed their root colonization potential in saline and non-saline soil. Our results provide evidence that AHLs modulate root architecture, and the inoculation of both AHL-producing Aeromonas spp. shows an elevated effect than that of non-AHL strain for plant growth and yield under salt stress. Therefore, the utilization of these bacteria as biofertilizer offers a sustainable solution for crop (wheat) cultivation in saline lands.

\section{MATERIALS AND METHODS}

\section{Bacterial Strains and Wheat Genotypes Used}

Three test strains Aeromonas spp., [SAL-12 (accession no. HG763856), SAL-17 (accession no. HG763857), SAL-21 (accession no. HG763858)], biosensor strain Chromobacterium violaceum CV026, reference strain Rhizobium leguminosarum strain 8401, and R. leguminosarum A34 which is a derivative of strain 8401 containing symbiotic plasmid pRL1J1, along-with the wheat genotypes NW-10-1111-7 (salt-tolerant genotype; STG), and NW-5-1212-I (salt-sensitive genotype; SSG) are mentioned in Table 1 with a short description and growth conditions. The $16 S$ rRNA gene sequences of Aeromonas spp. strains SAL-17, SAL-21, and SAL-12 were aligned to highly similar sequences using multiple sequence alignment, and phylogeny was determined by maximum likelihood method (Jukes and Cantor, 1969) using a MEGA6 software package (Kumar et al., 2016).

\section{Biochemical and Physiological Characterization}

The Aeromonas sp. strains used were already reported as PGPR (Rajput et al., 2018). For further characterization, they were tested for tolerance range for $\mathrm{NaCl}(0.5-10 \%), \mathrm{pH}$ (6$8)$, and temperature $\left(4-42^{\circ} \mathrm{C}\right)$. Biochemical tests were carried out as described previously (Miñana-Galbis et al., 2002): Gram staining, motility, glucose oxidation-fermentation, oxidase and catalase activity, production of a brown diffusible pigment, hydrogen sulfide production from cysteine and thiosulfate, acid production from carbohydrates, hydrolysis of urea, and utilization of substrates as sole carbon and energy sources. Arginine dihydrolase, lysine decarboxylase, and ornithine decarboxylase activity (Moeller's method) were determined as described by Smibert and Krieg (1994). The hemolytic activity of strains was tested by spot inoculating the cells onto nutrient agar plates containing $5 \%$ sheep blood. The plates were incubated at $28 \pm 2{ }^{\circ} \mathrm{C}$ and observed for hemolysis.

\section{Identification and Analysis for AHLs Detection of AHLs}

Initial screening of AHL production was done by the overlay assay (McClean et al., 1997). Briefly, $100 \mu \mathrm{l}$ of an overnightgrown culture of test strain was spot-inoculated onto a Luria broth (LB) agar plate. The indicator strain C. violaceum CV026 (mini Tn5 negative mutant for violacein production) was grown individually in TY medium, mixed with semi-solid LB agar $(0.7 \%)$ cells, and spread onto the test strain, and the plates were streaked with the reference strains. The bacterial strain SAL-12 was used as AHL negative control. The plates were incubated at $28 \pm 2^{\circ} \mathrm{C}$ for $24 \mathrm{~h}$ and observed for the development of purple color. The AHLs produced by test strains/reference strains diffused through the agar and stimulated violacein synthesis (blue/purple pigmentation) in C. violaceum CV026 which cannot synthesize its own AHLs.

For the confirmation of the AHL system in Aeromonas, a primer pair was designed to amplify $\mathrm{a} \approx 750$-bp sequence from the regulatory gene of the LuxR-type transcriptional regulator in Aeromonas spp. from the sequences available in the database. Lux gene was amplified using the primer pair $\mathrm{P} 1=5^{\prime}$-ATGAAACAAGACCAACTGCT-3 $3^{\prime} / \mathrm{P} 4=5^{\prime}-$ AAGCTTAATGCCACTGCTCACC- $3^{\prime}$ using the following conditions: initial $5 \mathrm{~min}$ denaturation at $95^{\circ} \mathrm{C}$, followed by 30 cycles at $95^{\circ} \mathrm{C}$ for $60 \mathrm{~s}, 57^{\circ} \mathrm{C}$ for $30 \mathrm{~s}, 72^{\circ} \mathrm{C}$ for $45 \mathrm{~s}$, and a final extension step of $72^{\circ} \mathrm{C}$ for $10 \mathrm{~min}$.

\section{TLC and ESI-MS/MS Analysis of AHLs}

Bacterial strains were individually grown at $28 \pm 2^{\circ} \mathrm{C}$ for 3 days in LB broth with constant shaking at $200 \mathrm{rpm}$. AHLs were extracted twice from spent supernatant using an equal volume of acidified ethyl acetate $(0.1 \%$ glacial acetic acid $\mathrm{v} / \mathrm{v})$ and confirmed by overlay assay as described earlier (Hanif et al., 2020). Extraction 
TABLE 1 | Bacterial strains, growth conditions, and wheat genotypes used in this study.

\begin{tabular}{|c|c|c|c|c|}
\hline Strain & Description & $\begin{array}{l}\text { Growth } \\
\text { conditions }\end{array}$ & Purpose & Source/References \\
\hline $\begin{array}{l}\text { Chromobacterium } \\
\text { violaceum } \\
\text { Cv026 }\end{array}$ & mini-Tn5 mutant of ATCC 31532; violacein negative & $\begin{array}{l}\text { LB }+ \text { kanamycin } \\
(25 \mu \mathrm{g} / \mathrm{ml}) \\
28 \pm 2^{\circ} \mathrm{C}\end{array}$ & $\begin{array}{l}\text { Biosensor/indicator strain for AHLs } \\
\text { detection; detect and respond to } \\
\text { AHLs }\left(\mathrm{C}_{4}-\mathrm{C}_{8} \text { in length) by producing }\right. \\
\text { purple pigment violacein }\end{array}$ & McClean et al., 1997 \\
\hline $\begin{array}{l}\text { Rhizobium } \\
\text { leguminosarum } \\
\text { A34 }\end{array}$ & $\begin{array}{l}\text { Derivative of strain } 8401 \text {; carries a symbiotic } \\
\text { plasmid } p R L 1 \mathrm{~J} 1\end{array}$ & $\begin{array}{l}\text { YEM/TY, } \\
28 \pm 2^{\circ} \mathrm{C}\end{array}$ & $\begin{array}{l}\text { Reference strain for } \mathrm{AHLS} \\
\text { production; produce } \mathrm{C}_{4}-\mathrm{C}_{8} \mathrm{HSLS}\end{array}$ & Downie et al., 1983 \\
\hline $\begin{array}{l}\text { Aeromonas sp. } \\
\text { strain SAL-17 }\end{array}$ & $\begin{array}{l}\text { Wheat rhizosphere isolates from Biosaline Research } \\
\text { Station-II (BSRS-II) Pakka Anna }\left(31^{\circ} 24 / \mathrm{N} \text { and }\right. \\
\left.73^{\circ} 05 / \mathrm{E}\right)\end{array}$ & $\begin{array}{l}\mathrm{LB}, \\
28 \pm 2^{\circ} \mathrm{C}\end{array}$ & Test strains & Rajput et al., 2018 \\
\hline $\begin{array}{l}\text { Aeromonas sp. } \\
\text { strain SAL-21 }\end{array}$ & $\begin{array}{l}\text { Wheat rhizosphere isolates from Biosaline Research } \\
\text { Station-II (BSRS-II) Pakka Anna }\left(31^{\circ} 24 / \mathrm{N} \text { and }\right. \\
\left.73^{\circ} 05 / \mathrm{E}\right)\end{array}$ & $\begin{array}{l}\mathrm{LB}, \\
28 \pm 2^{\circ} \mathrm{C}\end{array}$ & Test strains & Rajput et al., 2018 \\
\hline $\begin{array}{l}\text { Aeromonas sp. } \\
\text { strain SAL-12 }\end{array}$ & $\begin{array}{l}\text { Wheat rhizosphere isolates from Biosaline Research } \\
\text { Station-II (BSRS-II) Pakka Anna }\left(31^{\circ} 24 / \mathrm{N} \text { and }\right. \\
\left.73^{\circ} 05 / \mathrm{E}\right)\end{array}$ & $\begin{array}{l}\mathrm{LB}, \\
28 \pm 2^{\circ} \mathrm{C}\end{array}$ & Negative strain for AHLs & Rajput et al., 2018 \\
\hline \multicolumn{5}{|c|}{ Parentage of wheat genotypes used in this study } \\
\hline $\begin{array}{l}\text { Wheat } \\
\text { genotype }\end{array}$ & Genotype description & $\begin{array}{l}\text { Parentage/ } \\
\text { pedigree }\end{array}$ & Origin & References \\
\hline NW-10-1111-7 & Salt tolerant & $\begin{array}{l}\text { NARC- } \\
\text { 241/Bhittai- } \\
1111-7\end{array}$ & Pakistan & Saleem et al., 2015 \\
\hline NW-5-1212-I & Salt sensitive & $\begin{array}{l}\text { NARC } \\
\text { 41/Bhittai-18 } \\
\text { Pakistan }\end{array}$ & & Saleem et al., 2015 \\
\hline
\end{tabular}

and subsequent reverse phase-thin layer chromatography (RPTLC) of AHLs were performed as described (Imran et al., 2014; Ali et al., 2016) on glass-backed C18 reverse phase plates (Merck) developed with an overlay of the exponentially grown culture of CV026.

For electrospray ionization (ESI) analysis, the AHL extracts were purified by solid phase extraction (SPE) (Li et al., 2006), and ESI-mass spectra were obtained by infusion with $5 \%$ formic acid on a mass spectrometer (LTQ XL Linear Ion Trap Mass Spectrometer from Thermo Scientific, United States) equipped with and ESI probe. All conditions were set as described previously (Ali et al., 2016), and data were acquired in positive and negative total ion full-scan mode (mass scan range: $m / z 50-500$ ). Various AHL peaks produced during full scan were subjected to tandem mass spectrometry (MS/MS) to confirm their chemical structures based on the fingerprints of their daughter ion peaks produced during fragmentation. The structures of AHLs and the fragmentation schemes were generated using Chem Bio Draw Ultra 12.0. The functions of AHLs already reported in the literature were assigned to those detected in the present study.

\section{Plant Inoculation Assays}

Formulation of Halo-Tolerant PGPR Inoculum

Due to the difference in the AHL production ability and different PGPR activities of both strains (Rajput et al., 2018), the bacterial strains were inoculated individually; a consortium containing bacterial strains SAL-21 and SAL-17 was formulated as well. Before this, both strains were tested for compatibility by a standard well-cut method (Rajendran et al., 2011). After confirmation of compatibility, the bacteria were grown separately in LB medium overnight up to an optical density (OD) of 0.45 ; the cells were harvested by centrifugation and mixed (1:1 ratio) in $0.85 \%$ saline to get a consortium of halo-tolerant bacteria (PGPR-consortium) for plant inoculation. A non-AHLproducing Aeromonas sp. strain SAL-12 was used as negative control in pot experiment.

\section{Root Colonization and QS Detection Under Induced Salinity Under Monoxenic Condition}

Seeds of salt-tolerant wheat genotype (NW-10-1111-7) were surface sterilized with $2 \%$ sodium hypochlorite for $5 \mathrm{~min}$, washed thrice with sterile distilled water, and germinated in the dark in sterile plastic plates containing $1 \%$ water agar supplemented with $200 \mathrm{mM} \mathrm{NaCl}$ at $25 \pm 2{ }^{\circ} \mathrm{C}$. After germination, 3-dayold seedlings were inoculated with bacterial strains (SAL-17 and SAL-21) and grown for 10 days at day/night temperature of $25 / 20^{\circ} \mathrm{C}$ and light/dark periods of $16 / 8 \mathrm{~h}$. The roots were transferred to new LB agar plates overlaid with biosensor strain $\mathrm{CV} 026$ and incubated at $30 \pm 2{ }^{\circ} \mathrm{C}$. Another experiment was set up with three replicates for root colonization analysis under a confocal laser scanning microscope (CLSM) using the same conditions. The roots were detached from the seedlings after 10 days aseptically and stained for 4-5 min in 20-30 $\mu$ l methyl acridine orange dye. The roots were washed with sterile water and observed under a CLSM (Fluo view, FV 1000, Olympus) attached with a digital monitoring system for capturing the fluorescence image. The samples were excited using the argon-ion laser line 
at 502-525 $\mathrm{nm}$ (for acridine orange), and fluorescence of the samples was detected. The fluorescent images were captured using FluoView software (Olympus).

\section{Effect of AHL Treatment on Wheat Roots Under Axenic Condition}

Seeds of both wheat genotypes were surface sterilized with $2 \%$ sodium hypochlorite for $5 \mathrm{~min}$ and washed thrice with sterile distilled water. Purified AHL mixes $(200 \mu \mathrm{l})$ from both strains were mixed individually in $15 \mathrm{ml}$ of $0.8 \%$ water agar medium and poured as a thin layer onto the water agar plate. For the mix-AHLs treatment, AHL extracts from both strains were mixed in a 1:1 ratio and mixed in water agar before pouring into the plates. Sterilized seeds were placed on the plate and germinated in the dark. The experiment was conducted in a completely randomized design with four replicates each. At 7 days after germination, the seedlings were removed from agar, and the roots were washed with distilled water and scanned using Rhizoscanner (EPSON Perfection V700Photo, Epson America, Inc. United States), equipped with WinRHIZO software (Regent Instruments Co. Canada). The roots were also observed under a light microscope (Leica DMLS) for the development of root hairs, and photographic images were recorded using digital camera.

\section{Pot Experiment: Effect of AHL-Producing Aeromonas spp. on Wheat Growth in Saline Soil}

A pot experiment was carried out in sterilized saline soil (BSRSII) in the wheat growing season. The seeds of wheat genotypes were inoculated separately with AHL-producing Aeromonas spp. SAL-17 and SAL-21, a mix of both SAL-17 + SAL-21 (consortium), and non-AHL-producing Aeromonas sp. SAL-12. Non-inoculated seeds in saline soil and non-saline soil were set as controls. The experiment was set up in a completely randomized design with five replicates of each treatment, and the plants were grown in natural wheat growing season. The plants were evaluated for different stress-related and agronomic parameters at 45-50 days after germination, while yield data were recorded at maturity.

\section{Total Proline Contents}

Free proline contents from wheat leaves were measured according to the method of Bates et al. (1973). Fresh leaves (0.5 g) were extracted in $10 \mathrm{ml}$ of $3 \%$ sulfosalicylic acid. Then, $2.0 \mathrm{ml}$ of the filtrate was mixed with $2.0 \mathrm{ml}$ of acid ninhydrin, followed by $2.0 \mathrm{ml}$ of glacial acetic acid. The samples were incubated at $100^{\circ} \mathrm{C}$ for $60 \mathrm{~min}$ and cooled in an ice bath, and $4.0 \mathrm{ml}$ of toluene was added to the solution and mixed vigorously. The chromophorecontaining toluene was aspirated, and the absorbance read as $520 \mathrm{~nm}$ on a spectrophotometer (IRMECO U2020). Proline concentration in the samples was determined from a standard curve and calculated on a fresh weight basis.

\section{Nitrate Reductase Activity}

Nitrate reductase activity from wheat leaves was measured by homogenizing leaves in a chilled mortar and pestle with $100 \mathrm{mM}$ potassium phosphate buffer ( $\mathrm{pH}$ 7.4), containing
$7.5 \mathrm{mM}$ cysteine, $1 \mathrm{mM}$ ethylenediamine tetraacetic acid (EDTA), and $1.5 \%(\mathrm{w} / \mathrm{v})$ casein. The homogenate was centrifuged at $10,000 \times g$ for $15 \mathrm{~min}$ at $4^{\circ} \mathrm{C}$. Nitrate reductase activity was determined as described (Robin, 1979). The extract was incubated in a reaction mixture containing $100 \mathrm{mM}$ potassium phosphate buffer ( $\mathrm{pH} 7.4$ ), $10 \mathrm{mM}$ EDTA, $0.15 \mathrm{mM} \mathrm{NADH}$, and $0.1 \mathrm{M} \mathrm{KNO}_{3}$ at $30^{\circ} \mathrm{C}$ for $30 \mathrm{~min}$. The reaction was stopped by $100 \mathrm{~mL}$ of $1.0 \mathrm{M}$ zinc acetate. The absorbance of the supernatant was determined at $540 \mathrm{~nm}$ after diazotation of nitrite ions with $5.8 \mathrm{mM}$ sulfanilamide and $0.8 \mathrm{mM} \mathrm{N}$-(1-naphthyl)ethylenediamine-dihydrochloride.

\section{Chlorophyll Contents and Gas Exchange Parameters}

Chlorophyll a and b were determined using $500 \mathrm{mg}$ fresh leaf extracted overnight with $80 \%$ acetone and centrifuged at $10,000 \times g$ for $5 \mathrm{~min}$. The absorbance of the supernatant was estimated using a spectrophotometer at 480-, 645-, and 663-nm wavelength against the solvent, and chlorophyll contents were calculated according to Arnon (1949).

Measurements of transpiration rate (E) and stomatal conductance (gs) were made on the third leaf from the top of each plant using an infrared gas analyzer (Analytical Development Company, Hoddeson, United Kingdom) on a sunny day from 10 to 11 a.m.

\section{Morphological and Field Data}

The parameters studied for morphological data at 25 dpi were plant fresh weight and shoot and root length and at $75 \mathrm{dpi}$ were shoot and root (length, fresh weight, and dry weight) and plant biomass along with the weight of 1,000 grains. Five plants from each replicate and 15 plants per treatment were uprooted at maturity, and the mean was calculated for each treatment.

\section{Statistical Analysis}

Data were analyzed statistically by analysis of variance technique, using the Statistix (version 8.1) software, and the least significant difference test (Fisher LSD) at 5\% probability was used to compare the differences among treatment means. The data presented in this work are the average of at least 15 plants per treatment; means \pm standard deviations are given in the figures. Graphs were constructed using Microsoft Excel (2016) and assembled using Corel Draw (R 12). Pearson/Spearman's correlations were calculated at 1,000 bootstrap analysis at 0.05 level (two-tailed). Categorical principal component analysis was performed using IBM SPSS software package version 20 (SPSS, Inc. Chicago, IL, United States).

\section{RESULTS}

\section{Biochemical and Physiological Profiling of Aeromonas Species}

Cells of Aeromonas spp. SAL-21, SAL-17, and SAL-12 are motile and Gram-negative. Growth occurs at $25-37^{\circ} \mathrm{C}, 0-10 \%$ $\mathrm{NaCl}(\mathrm{w} / \mathrm{v})$, and $\mathrm{pH}$ 6.5-9.5. Optimum growth temperature is $28 \pm 2{ }^{\circ} \mathrm{C}$. All three strains are positive for oxidase and catalase tests. The brown pigment is not produced by any species. SAL17 
and SAL-12 are positive for alanopine dehydrogenase (ADH) and $\beta$-galactosidase tests but negative for lactate dehydrogenase $(\mathrm{LDH})$ and octopine dehydrogenase $(\mathrm{ODH})$. SAL-21 is negative for $\mathrm{ADH}, \mathrm{LDH}$, and $\mathrm{ODH}$ but positive for the $\beta$-galactosidase test. Only SAL-21 cannot hydrolyze urea. All strains produce $\mathrm{H}_{2} \mathrm{~S}$ and utilize sodium citrate and malonate except SAL-12. Acid is produced from arabinose, mannitol, sucrose, sorbitol, maltose, succinate, rhamanose, inositol, and melibiose from all Aeromonas spp. in this study. The $\beta$-hemolytic activity was not found in any strain. All the biochemical and the physiological test results of Aeromonas spp. strains have been summarized and compared with the already reported Aeromonas species in Table 2 for the phenotypic and the biochemical differentiations. The plant-growth-promoting traits of these Aeromonas spp. strains are already published (Rajput et al., 2018), and their phylogenetic tree is shown in Supplementary Figure S1.

\section{Analysis of AHLs}

The strains SAL-17 and SAL-21 produced purple color on LB agar plates overlaid with biosensor strain C. violaceum CV026, indicating the production of AHLs compared with the positive control (Figure 1A). AHLs were extracted from the cell-free supernatant of strains SAL-17 and SAL-21 and confirmed by plate overlay assay (Figure 1B). The strain SAL-12 did not show any purple color around the colony with the biosensor strain CV026. RP-TLC was further carried out to separate the extracted AHLs (Figure 1C). The comparison was done with the strain R. leguminosarum 8401 and a derivative of this strain named A34 containing pRL1J1 as reference for AHLs. Four spots were observed in the lane of SAL-17 and SAL-21 compared to six spots for pRL1J1 (Figure 1C). Both strains (SAL-17 and SAL-21) gave amplification with the Aeromonas Lux gene-specific primers, confirming the presence of LuxR-type regulators in them. The AHLs-negative strain SAL-12 did not show any amplification with these primers, indicating the absence of the Lux regulator.

AHL extracts were purified through SPE and were subjected to ESI-mass spectrometry analysis for the profiling of AHLs. The structure of the selected AHLs and their corresponding peaks were confirmed by MS/MS analysis (Tables 3, 4). When an extract of SAL-17 was analyzed, eight AHLs (C6-HSL, 3OH-C5-HSL, 3-OH-C6-HSL, 3-oxo-C7-HSL, C10-HSL, 3-oxoC10-HSL, 3-OH-C10-HSL, and 3-oxo-C12-HSL $+\mathrm{H}_{2} \mathrm{O}$ ) were observed, and their structures were confirmed by tandem mass spectrometry (Figures 2A,B). Only two AHLs were confirmed by MS/MS analysis, in the case of SAL-21 C6-HSL and 3oxo-C10$\mathrm{HSL}+\mathrm{H}_{2} \mathrm{O}$ (Figures 2A,B); the other two spots detected in TLC could not be detected in MS/MS analysis. Functional annotation of the AHLs was done by equating them with the published literature, and their putative roles were assigned (Table 4).

\section{Plant Inoculation Assays \\ Root Colonization Under Induced Salinity}

The development of purple color on the roots shows the bacterial attachment/colonization as seen by the production of AHLs during early seedling growth and root colonization (Figures 3A,B). Root colonization analysis by CLSM, carried out both in the salinized as well as non-salinized medium, showed the colonization of inoculated bacteria on the root surface and root hairs and their presence in close vicinity of the root epidermal cells under salt stress (Figure 3C). A higher number of cells were found on the root surface in the case of wheat grown under salt stress as compared (Figure 3B) to wheat grown under normal conditions (Figure 3D), while non-inoculated control plants did not show the presence of any bacterial cell on root surfaces (Figures 3E,F).

\section{Effect of Axenic Supplementation of AHL Extract on Seedling Growth and Root Morphologies}

Wheat seeds grown on AHL-supplemented water agar showed early seedling growth with longer roots and greener shoots compared to the seedlings grown without AHL supplementation (Figure 4A1). Microscopic observations of the root showed the development of more root hairs in roots grown in the presence of AHLs than those grown without AHLs (Figure 4A2).

The rhizoscan data show that the addition of AHLs in agar medium under salt stress significantly improved the root growth and the morphologies in both wheat genotypes (Figure 4B1). Both SSG and STG of wheat, treated either with AHLs of SAL-21 and SAL-17 or a mixture of both, showed a significant increase in different root parameters compared to the non-AHL-treated seedlings. Among all the AHL treatments, seedlings grown on AHL mixture showed the highest percent increase in all root parameters, and AHL extracts of strain SAL-17 showed the lowest. Furthermore, the response of the salt-tolerant genotype was comparatively higher than the salt-tolerant genotype under stress. The AHL-treated salt-sensitive genotype showed an increase of $35-86 \%$ in root length (Figure 4B1), 32-58\% in projected area (Figure 4B2), 4-61\% in surface area (Figure 4B3), $10-16 \%$ in average diameter (Figure 4B4), 20-47\% in root volume (Figure 4B5), 30-78\% in root tips (Figure 4B6), 58-117\% in forks (Figure 4B7), and 33-266\% in root crossing (Figure 4B8) over non-AHL-treated plants under salt stress, whereas the AHLtreated salt-tolerant genotype showed an increase of $27-74 \%$ in root length (Figure 4B1), 30-55\% in projected area (Figure 4B2), $5-67 \%$ in surface area (Figure 4B3), 12-15\% in average diameter (Figure 4B4), 16-40\% in root volume (Figure 4B5), 37-73\% in root tips (Figure 4B6), 52-110\% in forks (Figure 4B7), and $66-333 \%$ in root crossing (Figure 4B8) over non-AHLs-treated plants under salt stress.

\section{Effect of Aeromonas spp. Strain Inoculation on Wheat Growth in Saline Soil \\ Proline Contents and Nitrate Reductase Activity}

Proline accumulation and nitrate reductase activity were significantly higher in the leaves of inoculated plants compared to non-inoculated plants grown with and without salt stress in both genotypes. Overall, leaf proline content, nitrate reductase activity, and the photosynthetic performance of inoculated plants in STG were significantly higher than in SSG inoculated plants (Figure 5).

The analysis of treatment response shows that the increase in leaf proline content was maximum in both genotypes where a 
TABLE 2 | Key biochemical and physiological tests for the phenotypic differentiation of Aeromonas spp. strains SAL-17 and SAL-21 from reported species of genus Aeromonas.

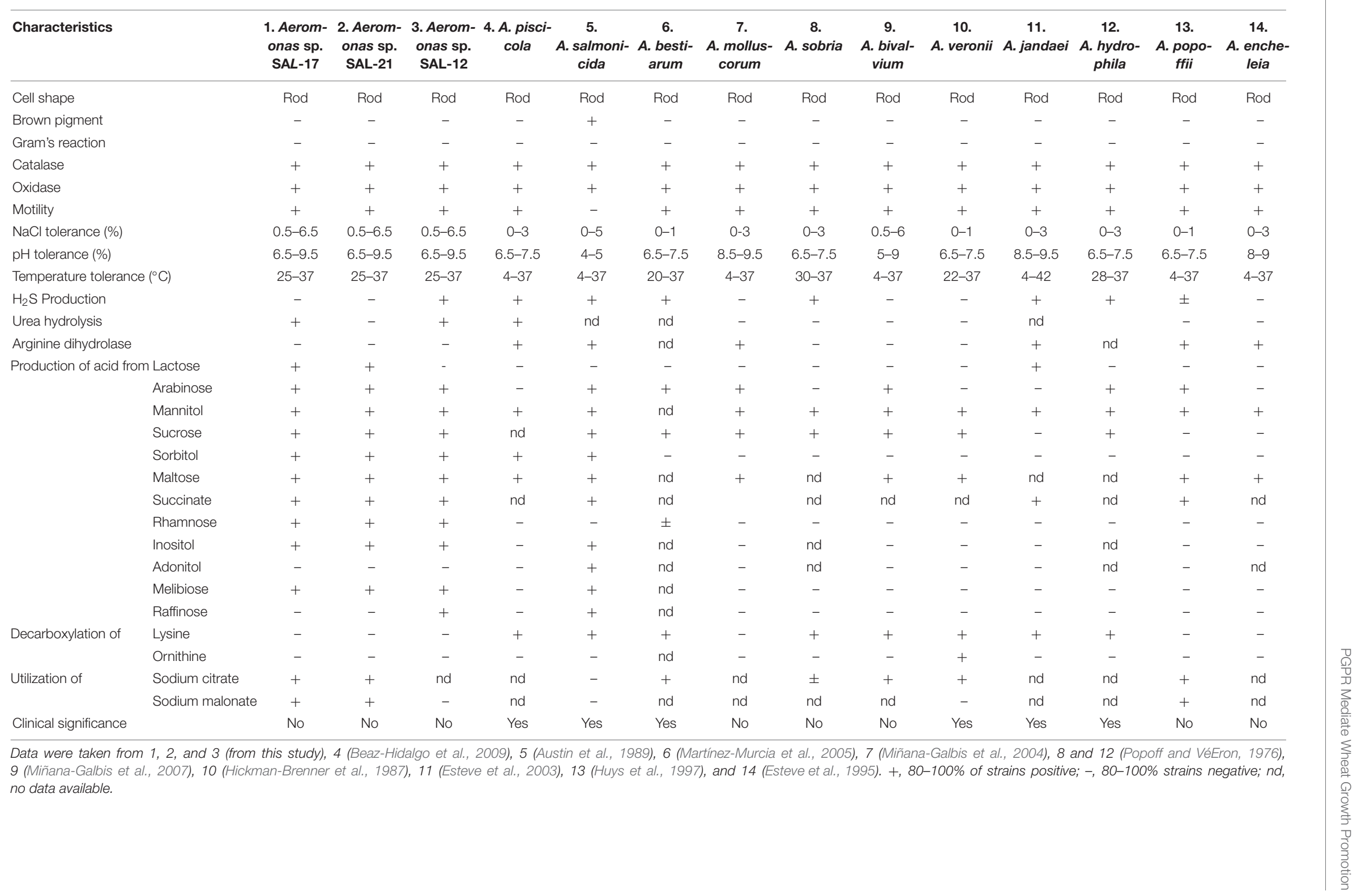


A

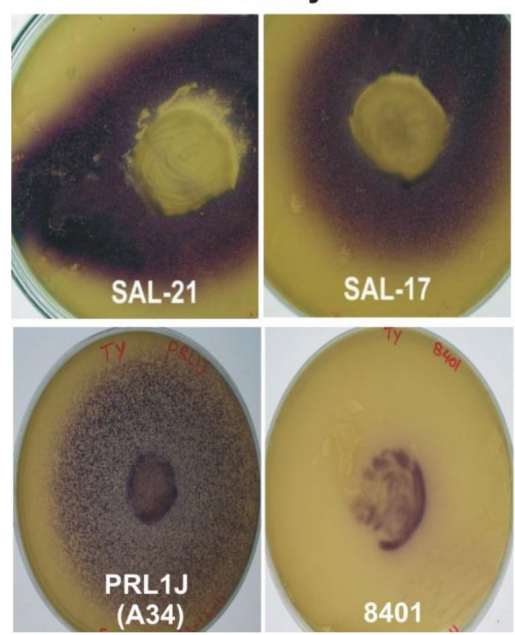

B

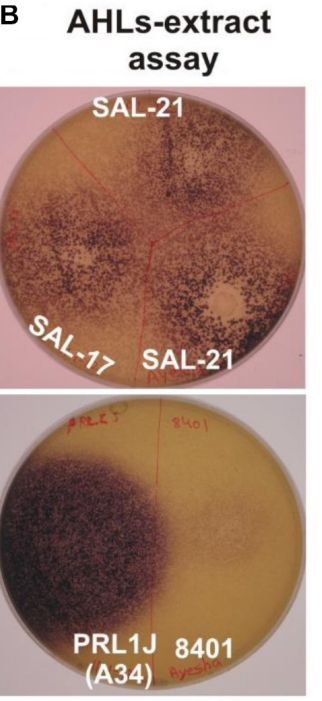

C TLC assay

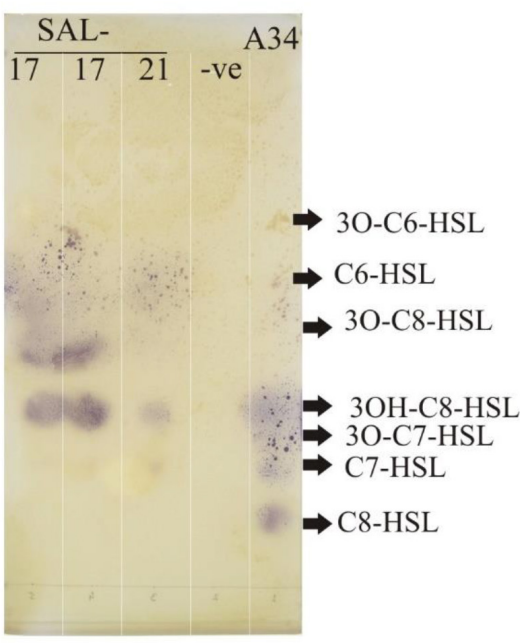

FIGURE 1 | (A) Acyl homoserine lactone (AHL) detection assay of Aeromonas spp. SAL-21 and SAL-17 with Chromobacterium violaceum CV026 showing purple coloration. Rhizobium leguminosarum A34 and 8401 refers to positive controls. (B) Plate assay of extracted AHLs. (C) Reverse phase-thin-layer chromatography of AHL extracts of SAL-17 and SAL-21 with the C. violaceum CV026 strain used as a biosensor and the R. leguminosarum strain A34 used as a positive control. From right, lane 1-positive control A34, lane 2-solvent control, lane 3-SAL-21, and lanes 4 and 5-SAL-17.

mixed inoculation of bacteria (consortium) was applied under saline soil, whereas the lowest was observed when both were grown without inoculation under normal soil (Figure 5A). NonAHL-producing Aeromonas sp. SAL-12 also showed an increase in proline contents, but this increase was significantly lower than in the other bacterial inoculation treatments.

Nitrate reductase activity (NR) was significantly higher in STG than in SSG irrespective of bacterial treatments or the soils. The plants inoculated with the bacterial consortium and those inoculated with SAL-17 showed the maximum NR activity and the highest percent increase over the respective noninoculated control. Similarly, SSG showed maximum NR activity in consortium-inoculated plants, although the activity was much lower than the corresponding treatment in STG (Figure 5B). The leaves inoculated with non-AHL-producing Aeromonas sp. SAL-12 showed a little increase in NR activities in both genotypes.

\section{Stomatal Conductance, Transpiration Rate, and Chlorophyll Contents}

Of the two genotypes, STG exhibited increased activities for all the gas exchange and photosynthetic parameters. The maximum response of inoculation was observed in the treatment where bacterial consortium was applied. In non-inoculated plants, stomatal conductance, transpiration rate, and chlorophyll contents were higher in normal soil compared to those in saline soil (Figures 5C-F).

Stomatal conductance was highest in STG, with an increase of $84 \%$ in the consortium, $57.6 \%$ in SAL-17, $24 \%$ in SAL-21, and $20 \%$ in SAL-12 inoculation, respectively, over the non-inoculated control. The salt-sensitive genotype showed an increase of $147.85 \%$ in the consortium, $120.36 \%$ in SAL-17, $103.57 \%$ in SAL21 , and $50.45 \%$ in SAL-12 inoculation, respectively (Figure 5C).
This shows that, although stomatal conductance was higher in STG, the relative percent increase after inoculation was significantly higher in SSG.

Transpiration rate showed a similar trend and was highest in STG with an increase of $54.5 \%$ in the consortium, $27 \%$ in SAL-17, 24.5 in SAL-21\%, and 18\% in SAL-12 inoculation, respectively, over the non-inoculated control. The salt-sensitive genotype showed an increase of $75.05 \%$ in the consortium, $32.53 \%$ in SAL-17, 29.04\% in SAL-21, and $21.26 \%$ in SAL-12 inoculation, respectively (Figure 5D).

Chlorophyll a band total chlorophyll contents were significantly high in STG plants after inoculation with the consortium. The improvement in chlorophyll contents was statistically less significant in SSG and other treatments (Figures 5E,F).

In general, the STG showed the maximum increase in all the stress parameters studied, but a comparative analysis of data revealed that the salt-sensitive genotype responded better to inoculation because the percentage increase was higher in SSG than in STG compared to the non-inoculated controls.

\section{Growth and Yield}

Analysis of growth and yield parameters of wheat showed a significant increase in inoculated wheat plants compared to non-inoculated controls (Figure 6) in both wheat genotypes. Overall, the salt-tolerant genotype inoculated with bacterial consortium showed the maximum growth and yield, whereas the non-inoculated salt-sensitive genotype in normal or saline soil showed the minimum.

The data regarding plant fresh weight (Figure 6A), root length (Figure 6B), and shoot length (Figure 6C) collected on the 25th day of inoculation showed a significant response of inoculation 
TABLE 3 | Liquid chromatography-tandem mass spectrometry analysis of acyl homoserine lactones (AHLs) in spent culture supernatant of Aeromonas spp. SAL-17 and SAL-21.

\begin{tabular}{|c|c|c|c|c|}
\hline Sr. \#. & AHL type & $m / z(M+H)^{+}$ & Relative abundance of isolated ions* & Daughter ions \\
\hline 1 & 3-OH-C5-HSL & 202 & +++ & $187,185,174,159,147,144,130,123,100,85$ \\
\hline 2 & C6-HSL & 200 & ++ & $185,182,172,158,156,144,130,114,102,88$ \\
\hline 3 & 3-OH-C6-HSL & 216 & + & $198,173,159,146,102,84$ \\
\hline 4 & 3-Oxo-C7-HSL & 228 & ++ & $210,199,186,172,159,145,130,120,102,84$ \\
\hline 5 & C10-HSL & 256 & ++++ & $238,228,214,188,186,172,159,130,102,88$ \\
\hline 6 & 3-Oxo-C10-HSL & 270 & +++ & $252,242,228,214,200,185,172,159,146,120,102,88$ \\
\hline 7 & 3-OH-C10-HSL & 272 & ++ & $254,228,214,200,186,172,159,146,118,102$ \\
\hline 8 & 3-oxo-C12-HSL & 316 & + & $298,272,246,222,212,184,166,152,106,102$ \\
\hline 9 & C6-HSL & 200 & + & $184,182,172,139,126,102,85$ \\
\hline 10 & 3-oxo-C10-HSL & 288 & ++++ & $273,270,260,244,214,188,174,160,144,140,125,106,102,88$ \\
\hline
\end{tabular}

in both genotypes, although the effect was significantly higher in STG than in SSG. A similar trend was observed for the data collected for growth parameters at 75 days after inoculation for shoot fresh weight (Figure 6D), root fresh weight (Figure 6E), shoot length (Figure 6F), and root length (Figure 6G).

A comparison of treatment means for the 1,000-grain weight (Figure $6 \mathbf{H}$ ) showed that the response of the salt-tolerant genotype was maximum in all treatments compared with that of the salt-sensitive genotype. Furthermore, the STG plants inoculated with consortium showed the maximum grain weight than all other inoculation treatments.

\section{The Relationship Among the Parameters}

The whole data were subjected for correlation analysis using SPSS, and a direct positive relationship of root length was found with other morphological parameters of root, i.e., projected area $\left(r=0.936^{* *}\right)$, surface area $\left(r=0.876^{* *}\right)$, average diameter $\left(r=0.896^{* *}\right)$, root volume $\left(r=0.912^{* *}\right)$, tips $\left(r=0.903^{* *}\right)$, forks $\left(r=0.958^{* *}\right)$, and crossings $\left(r=0.852^{* *}\right)$. The salt-tolerant genotype showed a specifically higher correlation coefficient ratio ( $r$ value). Plant fresh weight was found to be positively correlated with other plant morphological (dry weight and length), biochemical (nitrate reductase activity, proline contents), and physiological (chlorophyll contents) parameters $\left(r=0.621^{* *}\right.$ $\left.0.958^{* *}\right)$.

Linear regression effectively modeled the positive relationship of grain weight with the chlorophyll contents $\left(R^{2}=0.45\right.$ for SSG; $R^{2}=0.533$ for STG), accounting for $70-82 \%$ of the total variance. Quadratic regression was observed for grain weight with nitrate reductase activity $\left(R^{2}=0.858\right.$ for SSG; $R^{2}==0.880$ for STG) and proline contents $\left(R^{2}==0.917\right.$ for SSG; $R^{2}==0.942$ for STG) (Supplementary Figure S2).

The CAT-PCA and the PCA captured more than 75$90 \%$ of the variance and demonstrated the key genotype difference in both soils and inoculation treatments. The CATPCA (Figure 7A) demonstrated that all the observed plant traits/parameters loaded onto the positive quadrant were strongly positively correlated to each other $\left(R^{2}=0.838\right)$. The PCA showed that the inoculation response was similar in both genotypes, where the consortium-inoculated plants loaded positively while the non-inoculated plants loaded negatively on PCA (Figure 7B).

\section{DISCUSSION}

Various eco-physiological parameters of soil determine the microbial community and activity in the plant rhizosphere (Egamberdieva et al., 2010). Selection and subsequent plant inoculation of efficient PGPR strains compatible with local eco-physiological conditions can significantly improve a plant's nutritional status and their overall biotic and abiotic stress tolerance ability. Therefore, we selected wheat rhizosphere isolates from saline soil (BSRS-II) containing multiple plantgrowth-promoting traits. They were previously identified as Aeromonas spp. with plant-growth-promoting traits (Rajput et al., 2018). The strains were clinically non-significant (negative for the beta-hemolytic reaction) and hence could be used for further studies. Phylogenetic analysis showed their relatedness, but biochemical comparison showed their key differences from other Aeromonas spp. strains (Table 1).

This study reports two AHL-producing Aeromonas spp. from saline-soil rhizosphere, their mass spectrometry analysis, and the subsequent effect on plant growth. AHLs identified in SAL17 and SAL-21 strains include 3-OH-C5-HSL, C6-HSL, 3-OHC6-HSL, 3-oxo-C7-HSL, C10-HSL, 3-oxo-C10-HSL, 3-oxo-C10$\mathrm{HSL}+\mathrm{H}_{2} \mathrm{O}$, 3-OH-C10-HSL, and 3-oxo-C12-HSL $+\mathrm{H}_{2} \mathrm{O}$. There are various AHLs reported from genus Aeromonas (Supplementary Table S1), but six AHLs (3-OH-C5-HSL, 3OH-C6-HSL, 3-oxo-C7-HSL, 3-oxo-C10-HSL, 3-OH-C10-HSL, and 3-oxo-C12-HSL) identified in this study (Table 3) were not reported earlier, a feature that makes SAL-17 and SAL21 different from other Aeromonas species. Being different in the genus Aeromonas, we deduced the function of these six AHLs from already published studies where they have been detected from other bacterial species. The functional annotation of the detected AHLs (Table 4) in the Aeromonas spp. SAL-17 and SAL-21 showed that these AHLs are mainly involved in the induction of systemic resistance against various pathogens, synthesis of phytohormones, and plant growth promotion. Exclusively C6-HSL plays its role in the induction of systemic resistance against biotic and abiotic stresses, root colonization, and biofilm formation by bacteria, root growth, and development. C6-HSL, 3-oxo-C-10-HSL, and 3-oxo-C12HSL have a combined well-defined role against salt stress via the enhanced activity of superoxide dismutase (SOD), 
TABLE 4 | Functional annotation of acyl homoserine lactones (AHLs) in spent culture supernatant of Aeromonas spp. SAL-17 and SAL-21 compared to others reported in literature.

\begin{tabular}{|c|c|c|c|c|}
\hline $\begin{array}{l}\text { AHL types } \\
\text { detected in this } \\
\text { study }\end{array}$ & Putative role/function & Detected previously in bacteria & $\begin{array}{l}\text { Isolated from (host)or tested on } \\
\text { plant }\end{array}$ & References \\
\hline 3-OH-C5-HSL & Putative role in symbiosis & S. meliloti & $\begin{array}{l}\text { Alysicarpus bupleurifolius L. root } \\
\text { nodules }\end{array}$ & Zarkani et al., 2013 \\
\hline \multirow[t]{3}{*}{ C6-HSL } & $\begin{array}{l}\text { Production/regulation of phenazines, } \\
\text { siderophore, chitinases, proteases and } \\
\text { pyrrolnitrin, 2,4-DAPG, hydrogen } \\
\text { cyanide, } \\
\text { antifungal activity against pathogens, } \\
\text { induced systemic resistance, } \\
\text { systemic induction of ethylene- and } \\
\text { salicylic acid-dependent } \\
\text { defense-related genes, } \\
\text { increased plant resistance to early } \\
\text { infection, } \\
\text { improved germination, growth, } \\
\text { development, and productivity, } \\
\text { root elongation, alteration of auxin to } \\
\text { cytokinin ratio in roots and shoots, } \\
\text { root colonization, } \\
\text { synthesis of IAA, } \\
\text { elevated defense response }\end{array}$ & $\begin{array}{l}\text { Pseudomonas sp., } \\
\text { Burkholderia ambifaria, } \\
\text { P. chlororaphis, } \\
\text { Serratia liquefaciens, } \\
\text { Serratia plymuthica, } \\
\text { Pseudomonas fluorescens, } \\
\text { Serratia plymuthica }\end{array}$ & $\begin{array}{l}\text { Wheat and maize roots, } \\
\text { Lycopersicon esculentum, Brassica } \\
\text { napus L. roots, } \\
\text { transgenic Nicotiana tabacum, } \\
\text { Arabidopsis thaliana L. roots, } \\
\text { roots of Brassica napus subsp. Napus } \\
\text { L., } \\
\text { Cucumis sativus L., Phaseolus vulgaris } \\
\text { L., Lycopersicum esculentum L., } \\
\text { Chlorella vulgaris L. roots }\end{array}$ & $\begin{array}{l}\text { Wood et al., 1997; Chin-A-Woeng } \\
\text { et al., 2001; Zhou et al., 2003; Müller, } \\
\text { 2006; Schuhegger et al., 2006; Wei } \\
\text { and Zhang, 2006; von Rad et al., 2008; } \\
\text { Müller et al., 2009; Pang et al., 2009; B } \\
\text { et al., 2012; Cheng et al., 2018; Hu } \\
\text { et al., } 2018\end{array}$ \\
\hline & $\begin{array}{l}\text { Low concentration protected against } \\
\text { salt stress via enhanced activity of } \\
\text { SOD, POD, CAT, and higher } \\
\text { accumulation of MDA, } \\
\text { stress-responsive, signal transduction } \\
\text { and regulation and biosynthesis-related } \\
\text { proteins }\end{array}$ & NA & Arabidopsis thaliana L. Col-0 roots & Ding et al., 2016 \\
\hline & $\begin{array}{l}\text { Plant growth promotion including and } \\
\text { development of lateral roots and } \mathrm{NO}^{-} \\
\text {accumulation in calyptra, enhanced } \mathrm{K}^{+} \\
\text {uptake through membrane } \\
\text { hyper-polarization }\end{array}$ & NA & Hordeum vulgare L. roots & Rankl et al., 2016 \\
\hline $\begin{array}{l}\text { 3-OH-C6-HSL, } \\
\text { 3-Oxo-C7-HSL }\end{array}$ & $\begin{array}{l}\text { Antifungal activity, } \\
\text { production of pyrrolnitrin, chitinase, } \\
\text { protease siderophores and hydrogen } \\
\text { cyanide, } \\
\text { rhizosphere colonization, biocontrol } \\
\text { activity }\end{array}$ & $\begin{array}{l}\text { Serratia sp., } \\
\text { Ochrobactrum sp. }\end{array}$ & $\begin{array}{l}\text { Triticum aestivum } \mathrm{L} \text {. stems, } \\
\text { Phaseolus vulgaris } \mathrm{L} \text {. roots }\end{array}$ & Liu et al., 2010; Imran et al., 2014 \\
\hline
\end{tabular}


TABLE 4 | Continued

\begin{tabular}{|c|c|c|c|c|}
\hline $\begin{array}{l}\text { AHL types } \\
\text { detected in this } \\
\text { study }\end{array}$ & Putative role/function & Detected previously in bacteria & $\begin{array}{l}\text { Isolated from (host)or tested on } \\
\text { plant }\end{array}$ & References \\
\hline $\begin{array}{l}\text { 3-oxo-C10-HSL, } \\
\text { 3-oxo-C12-HSL }\end{array}$ & $\begin{array}{l}\text { Biofilm formation, } \\
\text { expression of defense-related, } \\
\text { stress-responsive, flavonoid synthesis, } \\
\text { phytohormonal and regulatory genes, } \\
\text { salt stress protection mechanism, } \\
\text { overall growth promotion }\end{array}$ & $\begin{array}{l}\text { Pseudomonas putida, } \\
\text { Sinorhizobium meliloti, } \\
\text { Pseudomonas aeruginosa, } \\
\text { Burkholderia graminis }\end{array}$ & $\begin{array}{l}\text { Lycopersicon esculentum } \mathrm{L} \text {. roots, } \\
\text { Medicago truncatula } L \text { roots, } \\
\text { transgenic } L \text { cycopersicum esculentum } \mathrm{L} \\
\text { (Lasl) }\end{array}$ & $\begin{array}{l}\text { Steidle et al., 2001; Steidle et al., 2002; } \\
\text { Mathesius et al., 2003; Barriuso et al., } \\
2008\end{array}$ \\
\hline \multirow[t]{4}{*}{ C10-HSL } & $\begin{array}{l}\text { Post-embryonic root development } \\
\text { including lateral and primary root } \\
\text { growth and root hair development, } \\
\text { adventitious roots formation through } \\
\mathrm{H}_{2} \mathrm{O}_{2}, \mathrm{NO} \text { and cGMP signaling, } \\
\text { expression of IAA-responsive genes, } \\
\text { induced systemic resistance and root } \\
\text { development }\end{array}$ & NA & $\begin{array}{l}\text { Arabidopsis thaliana } L \text {. roots, } \\
\text { Vigna radiata } L \text {. roots, } \\
\text { Hordeum vulgare L. roots }\end{array}$ & $\begin{array}{l}\text { Ortíz-Castro et al., 2008; Bai et al., } \\
\text { 2012; Hu et al., 2012; Sieper et al., } \\
2014\end{array}$ \\
\hline & $\begin{array}{l}\text { Calmodulin-regulated primary root } \\
\text { growth }\end{array}$ & NA & Arabidopsis thaliana L. roots & Zhao et al., 2015 \\
\hline & $\begin{array}{l}\text { Enhanced activity of critical } \\
\text { photosynthetic enzymes including } \\
\text { rubisco, maximal and actual } \\
\text { photochemical efficiency was also } \\
\text { enhanced }\end{array}$ & NA & Chlorella vulgaris roots & Dou et al., 2017 \\
\hline & $\begin{array}{l}\text { Increased plant resistance against } \\
\text { B. cinerea via jasmonic acid signaling } \\
\text { under elevated } \mathrm{CO}_{2}\end{array}$ & NA & Lycopersicum esculentum L. leaves & Hu et al., 2020 \\
\hline 3-OH-C10-HSL & $\begin{array}{l}\text { Root colonization in microcolonies, } \\
\text { plant growth promotion, inhibition of } \\
\text { plant defense responses }\end{array}$ & Acidovorax radicis N35 & Hordeum vulgare L. roots & Han et al., 2016 \\
\hline
\end{tabular}



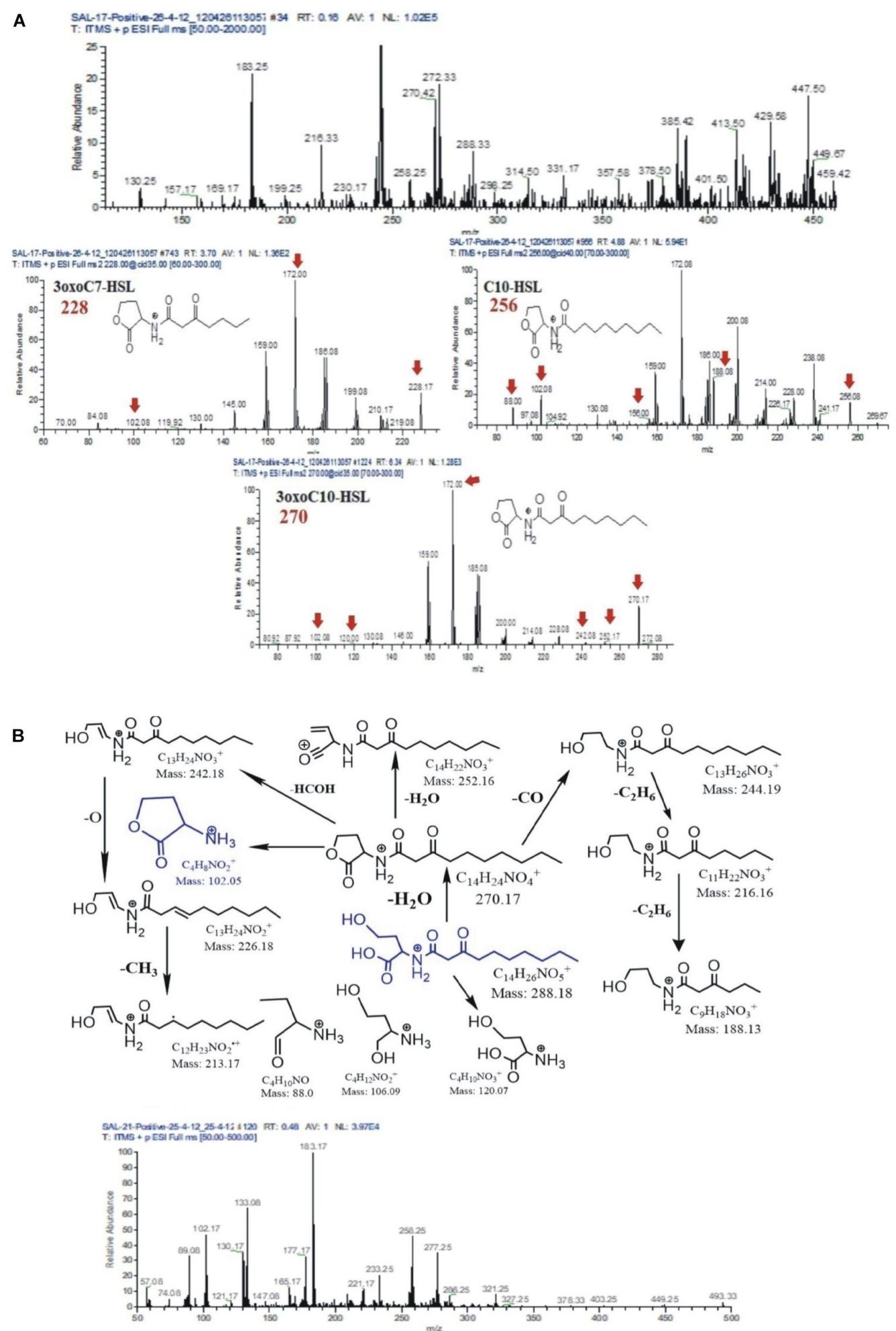

FIGURE 2 | (A) Mass spectrometry chromatogram (full MS) with peaks at $[\mathrm{M}+\mathrm{H}]^{+},\left[\mathrm{M}+\mathrm{H}+\mathrm{H}_{2} \mathrm{O}\right]^{+}$, and $[\mathrm{M}+\mathrm{Na}]^{+}$of acyl homoserine lactones (AHLs) extracted from strain SAL17. Protonated AHL $[\mathrm{M}+\mathrm{H}]^{+}$peaks were at a very low intensity. The peaks were identified as $\left[\mathrm{M}+\mathrm{H}+\mathrm{H}_{2} \mathrm{O}\right]^{+}$and $[\mathrm{M}+\mathrm{Na}]^{+}$for the presence of AHLs by adding a water molecule or the formation of sodium adducts. (B) Fragmentation pattern of AHLs 3oxoC10-HSL m/z 288. All daughter ions generated from the fragmentation of $\mathrm{m} / \mathrm{z} 288$ are unambiguously assigned (above). Mass spectrometry chromatogram (full MS) with peaks at $[\mathrm{M}+\mathrm{H}]^{+},\left[\mathrm{M}+\mathrm{H}+\mathrm{H}_{2} \mathrm{O}\right]+$, and $[\mathrm{M}+\mathrm{Na}]^{+}$of AHLs extracted from strain SAL21 (below). Protonated AHLs $[\mathrm{M}+\mathrm{H}]^{+}$peaks were at a very low intensity. The peaks were identified as $\left[\mathrm{M}+\mathrm{H}+\mathrm{H}_{2} \mathrm{O}\right]^{+}$ and $[\mathrm{M}+\mathrm{Na}]^{+}$for the presence of AHLs by adding a water molecule or the formation of sodium adducts. 

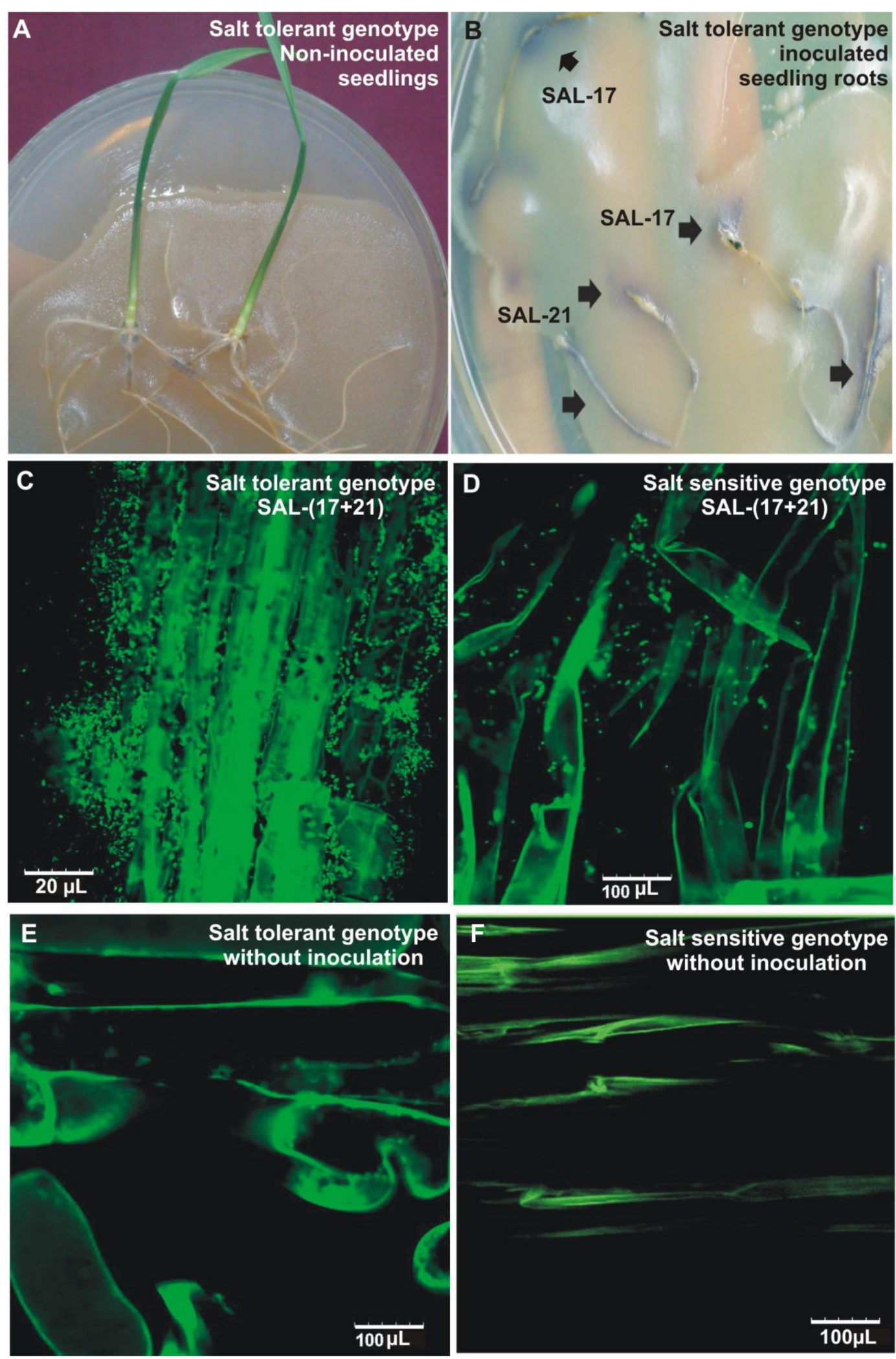

FIGURE 3 | Root colonization of salt-tolerant wheat genotype by bacterial inoculation and subsequent detection by plate overlay assay (A,B). Confocal microscopic images of salt-tolerant (C) and salt-sensitive (D) wheat roots inoculated with Aeromonas spp. bacterial consortium under salt stress. Non-inoculated salt tolerant (E) and salt-sensitive (F) genotype grown in salt stress are shown as controls. 
peroxidase (POD), and catalase (CAT) enzymes. 3-OH-C6-HSL is known to induce the production of antifungal metabolites by root-colonizing microbes, whereas 3-oxo-C7-HSL assists in the colonization process, and it may serve as biocontrol component in the rhizosphere. The signal molecules $3-\mathrm{OH}$ C6-HSL, 3-oxo-C7-HSL, 3-oxo-C-10-HSL, and 3-oxo-C12-HSL have been shown to protect against biotic and abiotic stresses. Furthermore, their role in biofilm formation, root colonization, and development of lateral and primary roots has also been described. The signal molecules C10-HSL and 3-OH-C1-HSL have been reported to control the primary and the secondary growth of root and colonization and the induction of plant defense response. Furthermore, they have a well-defined role in root growth and development, along with a significant impact on photosynthesis, induced stress resistance, and plant hormone signaling pathways. 3-Oxy-C10-HSL helps in biofilm formation and improves the growth of adventitious roots and the expression of indole-3-acetic acid (IAA)-responsive genes, while $3-\mathrm{OH}-\mathrm{C} 10-\mathrm{HSL}$ mediates plant root colonization, growth promotion, and induction of defense response. 3-Oxo-C12-HSL serves in biofilm formation and expression of stress-related, hormonal, and regulatory genes. The function of 3-OH-C5-HSL is not mentioned in the literature, but studies suggest that it might have some role in symbiosis as stated by Zarkani et al. (2013). The detection of this AHL type from Aeromonas spp. in the present study suggests that it might have some other functions in plants rather than just symbiosis. The same AHL from different bacteria exhibits fairly similar functions; detailed molecular studies are required for the validation of these functions.

The root colonization potential of a bacterium is necessary to develop a successful interaction with plant, and bacteria use AHL-mediated synchronized response to design and establish an efficient interaction between the host and its associated symbionts (Schenk and Schikora, 2015). Both strains (SAL-21 and SAL-17) possess IAA production ability (Rajput et al., 2018) and AHL production (this study) and exhibited their colonization ability on wheat roots in different experiments, i.e., confocal microscope analysis and plate assay. The confocal analysis showed that bacterial colonization is a little affected in the presence of salt. Furthermore, a modified plate overlay assay validated the root colonization and purple color, along with the growing seedling root, displaying that AHLs are being produced and might have a robust role in root development. AHL-mediated root colonizing
A1

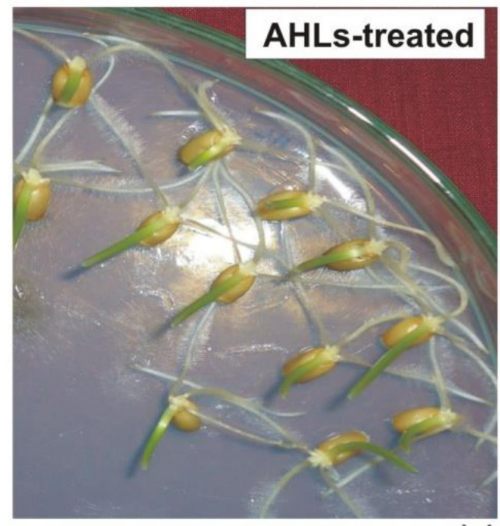

A2

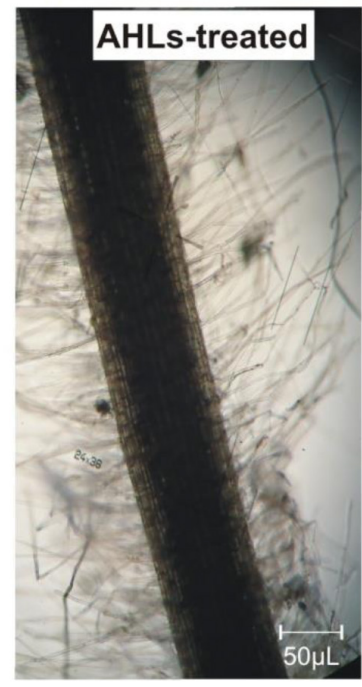

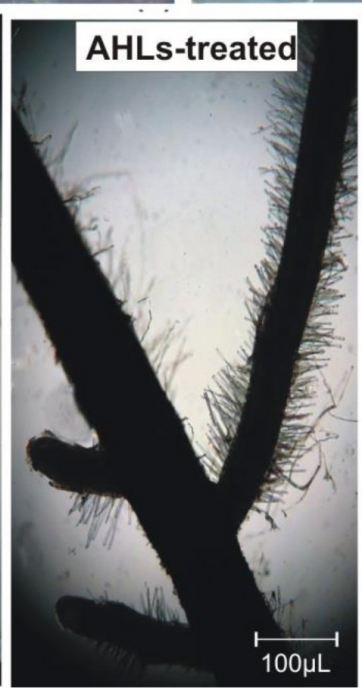




\section{Salt sensitive genotype Salt tolerant genotype}

B1

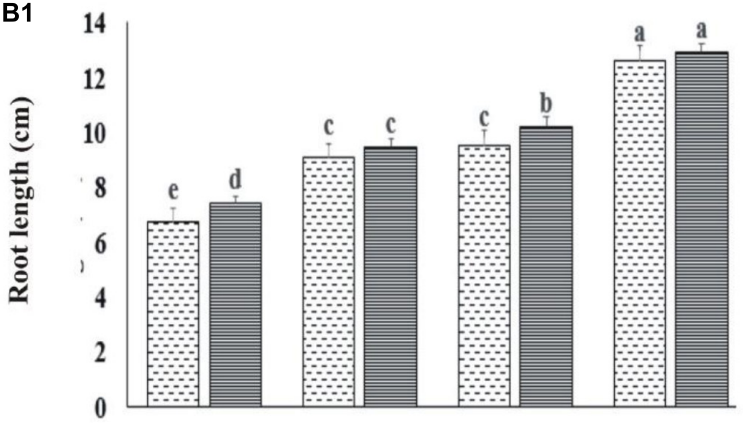

B3 $\quad \begin{array}{r}1.8 \\ \\ 1.6\end{array}$

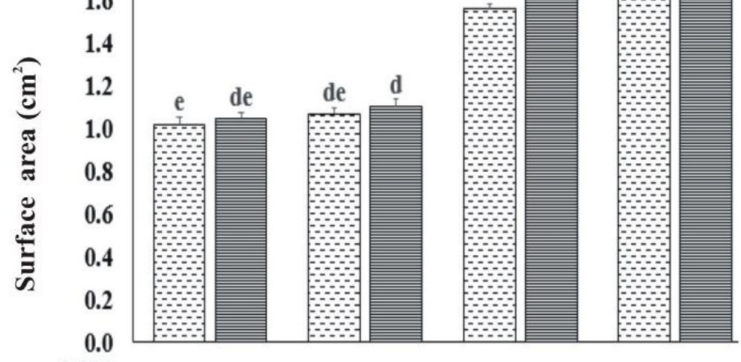

B5

B5 $\begin{array}{r}0.020 \\ 0.018\end{array}$
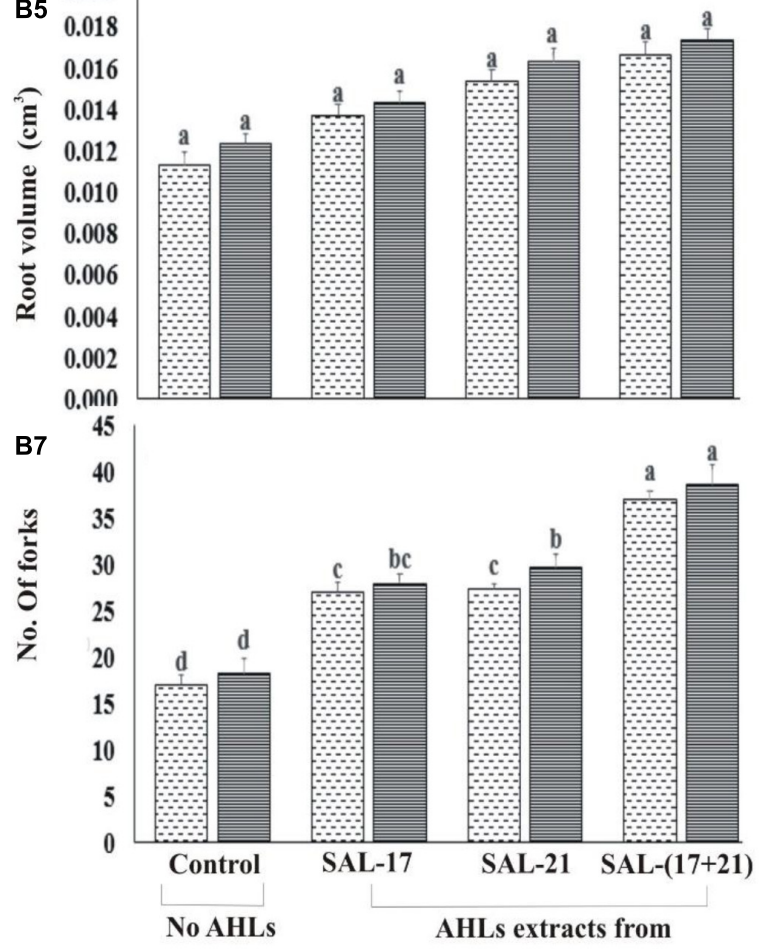
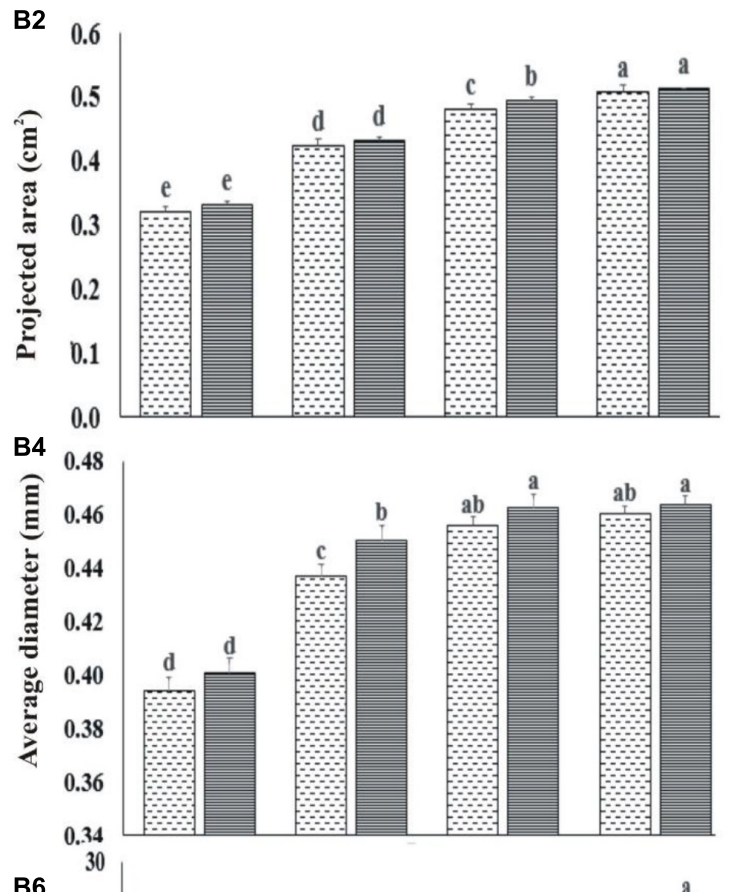

B6
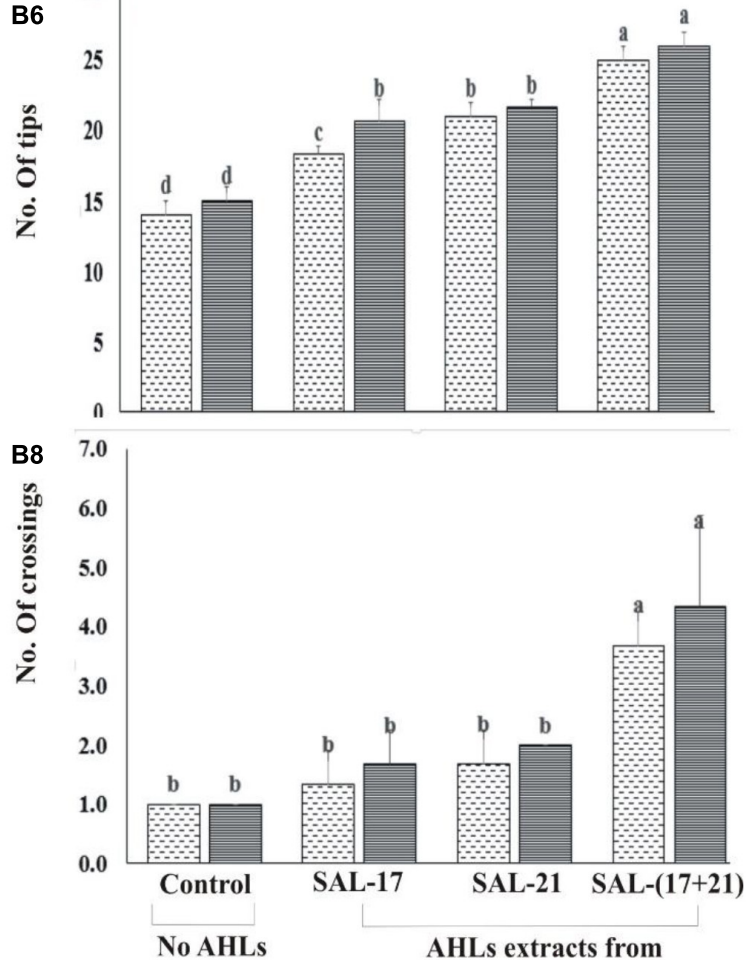

FIGURE 4 | (A1,A2) Effect of acyl homoserine lactone (AHL) supplementation on the seedling growth of wheat (A1) and AHL-mediated root hair development (A2) compared to control wheat seeds grown on water agar. The pictures were photographed at $\times 100$ magnification and then cropped to remove the background. (B1-B8) Effect of AHL supplementation on 10-day-old wheat roots under induced salinity (200 mM NaCl) compared to non-treated control in terms of (B1) root length, (B2) projected area, (B3) surface area, (B4) average diameter, (B5) root volume, (B6) number of tips, (B7) number of forks, and (B8) crossings. Values are the mean of four replicates. Bars represent standard deviation. Values sharing the same letter do not differ significantly $(P \leq 0.01)$ according to Fisher's least significant difference test. 


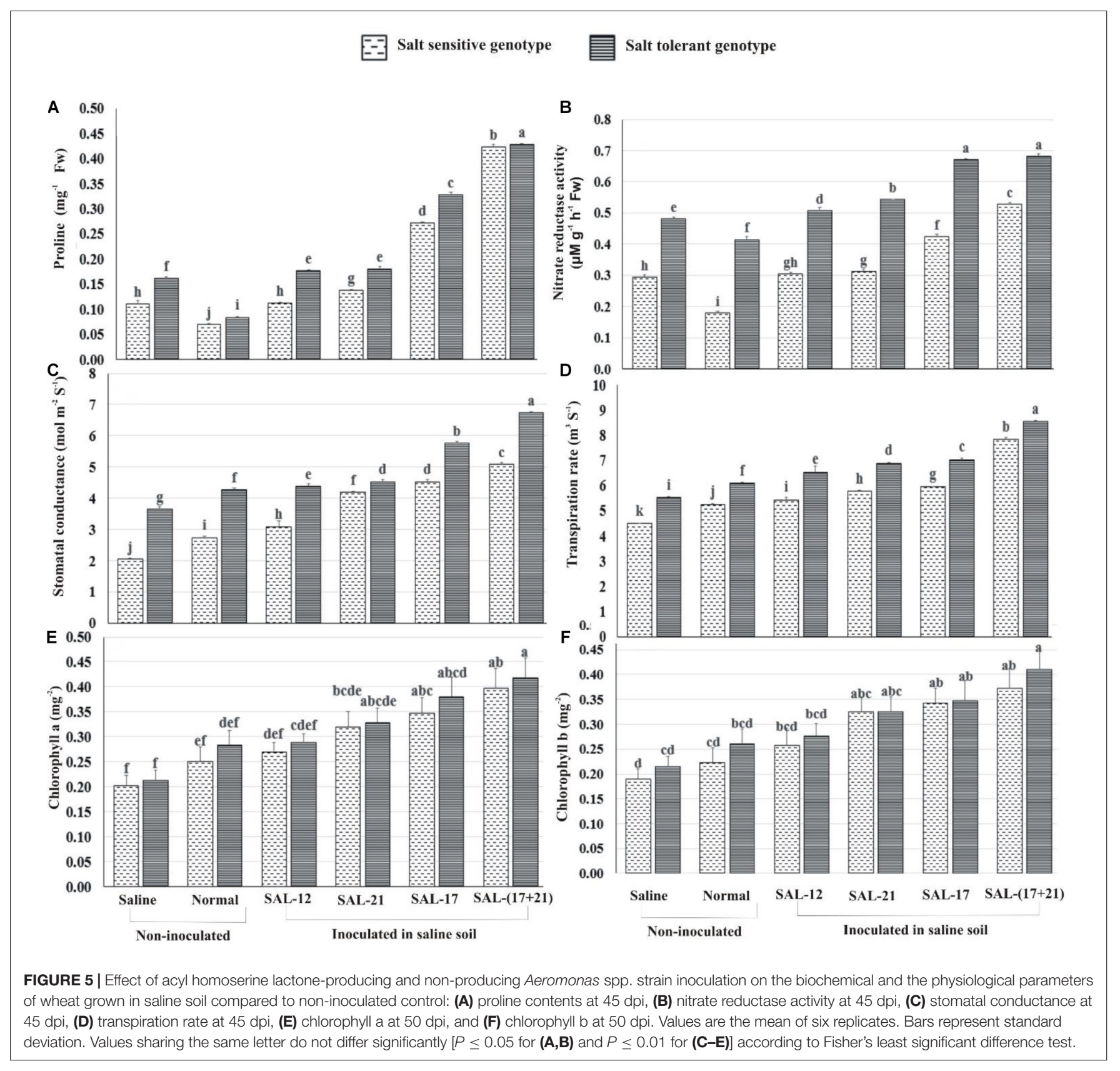

ability has been previously reported in rhizobia and genus Pantoea (Sutherland, 2001; Koutsoudis et al., 2006).

The root overlay assay revealed a likely role of AHLs in early root growth, which was further confirmed in a plate assay where purified AHLs were applied in growth medium and seeds were grown without bacterial inoculation. The data regarding root morphology establish the fact that the increase in root growth is the function of AHLs rather than of IAA. The plate overlay assay of extracted AHLs, RP-TLC analysis, and SPE steps ruled out the likelihood of the presence of IAA traces in the AHL extracts. The AHL extracts of these strains contain C6-HSL, which has a well-reported function in primary root elongation, auxin/cytokinin ratio alteration, transcriptional regulation, and biomass improvement (von Rad et al., 2008). The other AHL in the extract was C10-HSL, which enhances lateral root growth (Bai et al., 2012; Zhao et al., 2015) and shoot growth (Götz et al., 2007) in different plants. Purified AHL extracts from Bradyrhizobium sp. strain SR-6, which produces a wide variety of AHLs including C6-HSL, C10-HSL, 3-oxo-C10-HSL, 3-oxo-C12HSL, etc., significantly improved root hair development in wheat, along with increased nodulation in soybean (Ali et al., 2016).

Plant response was further evaluated by strain inoculation in saline soil. An IAA-positive but AHL-non-producing Aeromonas sp. strain SAL-12 indigenous to saline soil (Rajput et al., 2018) was used for comparison of inoculation response. SAL-12, along with both AHL-producing Aeromonas spp. SAL-17 and 


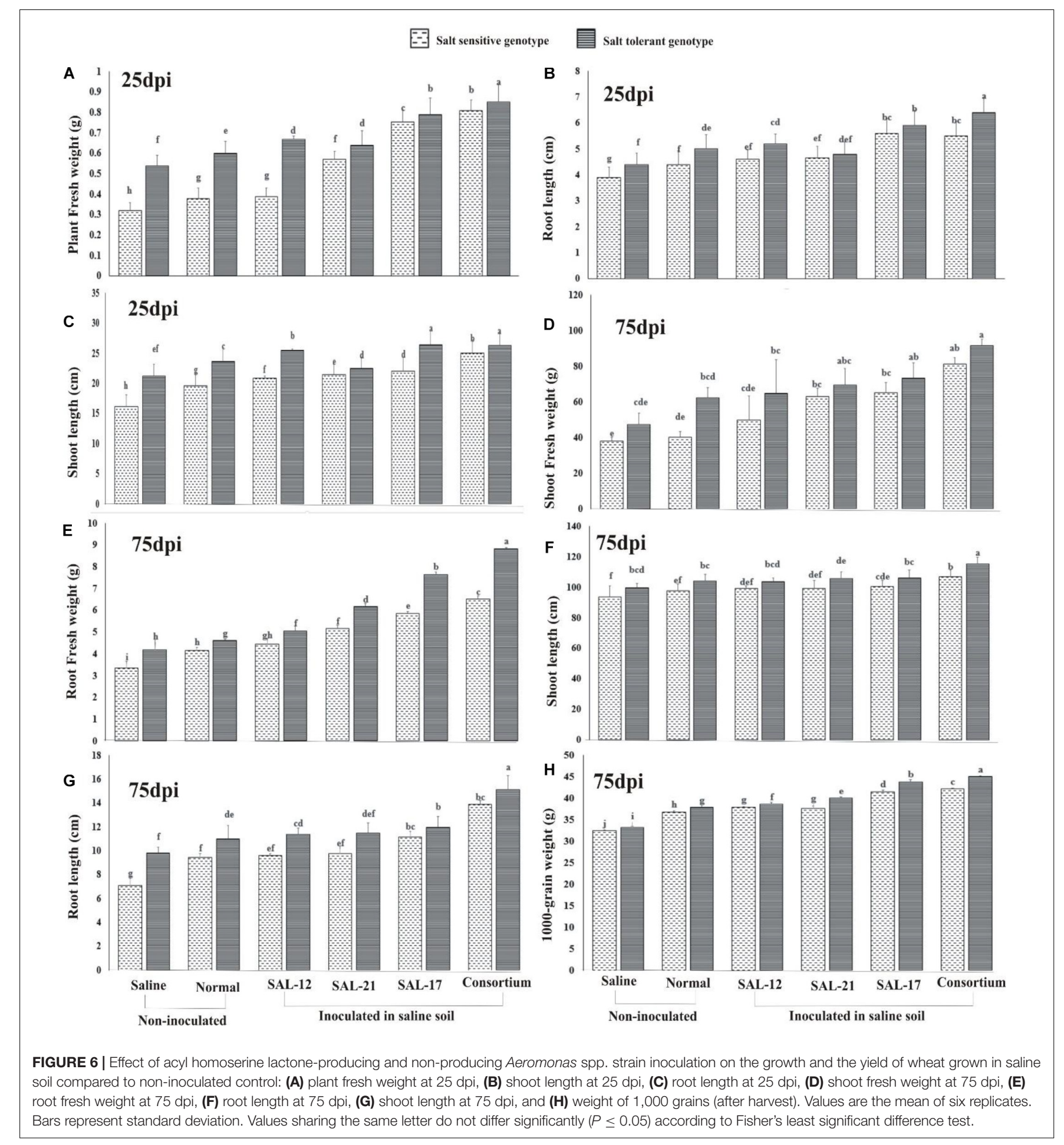

SAL-21, also exhibits ACC deaminase activity. IAA is a plant hormone that is involved in the stimulation of plant growth, and ACC deaminase has a well-known function in salt stress mitigation via the cutting synthesis of ethylene (Ahmad et al., 2011; Arshadullah et al., 2017; Sarkar et al., 2018; Afridi et al., 2019; Bharti and Barnawal, 2019; del Carmen Orozco-Mosqueda et al., 2020). Both these traits are a characteristic feature of any PGP candidate species because some studies have shown a synergistic effect of bacterial IAA and ACC deaminase. Both IAA and ACC deaminase have direct positive effects on root growth and root hair development, which help to enhance water and nutrient absorption from the soil (Príncipe et al., 2007). Our plant inoculation data demonstrated the significance of AHLs for plant growth under stress along with the role of 


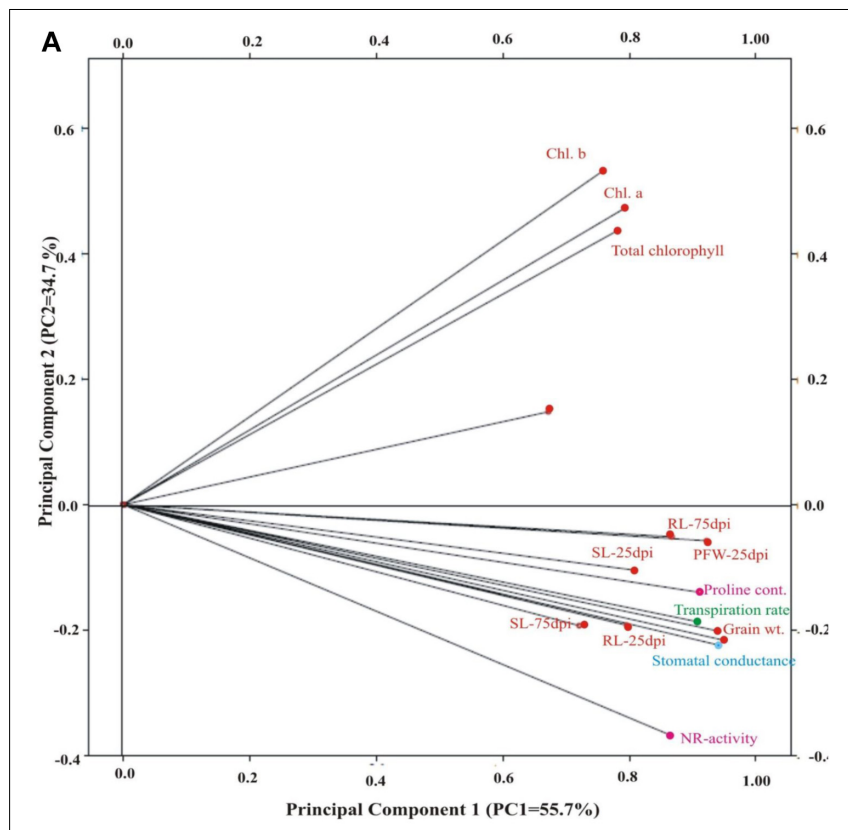

B Salt sensitive genotype Salt tolerant genotype

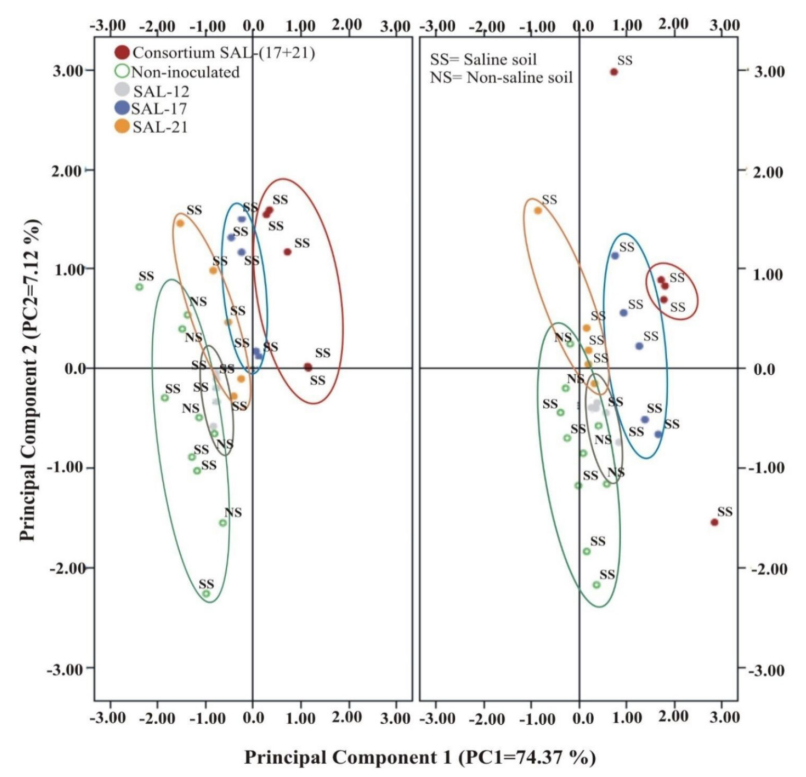

FIGURE 7 | (A,B) Categorical principal component analysis (CAT-PCA) of various plant traits measured across salt-tolerant and salt-sensitive genotypes grown in saline soil after different bacterial inoculation treatments (total variance explained: $90 \% ; \mathrm{PC} 1=55.7 \%, \mathrm{PC2}=34.7 \%)$. CAT-PCA is a non-linear PCA. Factor loadings in PC1 and PC2 are presented as vectors using external scale. PCA showing the response of salt-tolerant and salt-sensitive genotypes toward bacterial inoculation in saline soil compared to non-inoculated controls; loaded as genotypes (total variance explained : $81 \%$; $\mathrm{PC} 1=74 \%, \mathrm{PC} 2=7 \%)$.

IAA and ACC deaminase. For instance, if SAL-17 produces a wide variety of AHLs and higher IAA than SAL-21 and SAL-12, the response toward SAL-17 single inoculation and a mix inoculation (SAL-17 + SAL-21) was more pronounced on different biochemical, physiological, and growth parameters of wheat. AHLs directly or indirectly induce stress resistance in plants through QS-mediated production of metabolites (Ryu et al., 2013). It has been reported that inoculation of 3-oxoC12-HSL-producing bacterial strains induce salt stress tolerance, metabolic regulation, and phytohormone response in tomato and Medicago truncatula (Mathesius et al., 2003; Barriuso et al., 2008). The data from this study have presented many folds increase in the NR activity. NR is the enzyme responsible for nitrate assimilation and the production of NO in plants (ChamizoAmpudia et al., 2017). NR-mediated NO also has been reported as a key signaling molecule in leaf shape development (Pan Q.-N. et al., 2019), root geotropism (Vazquez et al., 2019), and various stress responses by plants. Although purified AHLs were not used in the experiment, still we speculate that AHLs have some role in the regulation of NR activity, which in turn induces salt stress tolerance in wheat because NR activity and proline contents directly correlate with AHL production. PGPR has a documented role to accumulate higher proline in plants under stress (Jha and Subramanian, 2014; Kumari et al., 2015; Singh and Jha, 2016b), and this study advocates this role along with some plausible role of AHLs, although it is still unclear how plants perceive these signals and how many are responsible to elicit these responses in plants. However, plants inoculated with the bacterial consortium (SAL-17 + SAL-21) showed a significantly $(P \leq 0.05)$ higher response and a maximum percent increase for all parameters in both genotypes of wheat. Further experiments using purified and inclusive inoculum for each kind of AHL with different concentrations and gene knockout studies can elucidate the role of individual AHLs on plant growth.

The data regarding stomatal conductance, transpiration rate, and photosynthetic pigments show that these parameters were significantly increased $(P \leq 0.05)$ in inoculated plants in both wheat genotypes under salt stress, wherein plants inoculated with AHL-producing Aeromonas sp. strains (SAL17 and SAL-21) showed a better response in terms of percent increase than the plants inoculated with non-AHL-producing Aeromonas sp. strain (SAL-12). This may be attributed to the contribution of AHLs in the overall plant response. Salinity usually causes osmotic stress in plants (Upadhyaya et al., 2013), which leads to stomatal closure by altering the turgor potential of the guard cells. It is a feedback process to prevent water loss via transpiration (Buckley and Mott, 2013), but it also blocks the passage for $\mathrm{CO}_{2}$, causing the photosynthetic activity to decrease. Not by themselves but the degraded products of AHLs have been reported to enhance stomatal conductance and transpiration rate in mung bean (Joseph and Phillips, 2003) because AHLs are not stable in the soil and readily degrade into their active constituents (Wang and Leadbetter, 2005). As acyl-HSLs in the rhizosphere are degraded, the bioavailability of nutrients to the roots and root-associated bacteria increases, which indirectly increases transpiration and growth (Joseph and Phillips, 2003). PGPRmediated improvement in chlorophyll pigments and overall photosynthetic capacity is well established (Babaei et al., 2017; Afridi et al., 2019; Azarmi-Atajan and Sayyari-Zohan, 2020; Ji et al., 2020). A meta-analysis of 561 studies has suggested 
the positive role of $\mathrm{PGPR}$ inoculation in $\mathrm{K}^{+} / \mathrm{Na}^{+}$ratio ion homeostasis, $\mathrm{Na}^{+}$exclusion, and enhanced photosynthetic activity (Pan J. et al., 2019). Moreover, inoculated Aeromonas spp. strains also produce IAA.

Along with the biochemical and the physiological parameters, the growth and the yield parameters of plants were significantly $(P \leq 0.05)$ improved in inoculated plants of both genotypes as compared to the non-inoculated control. It could be an accumulative effect of multiple PGP and stress tolerance traits and a wide range of AHLs. A significant contribution of AHLs becomes obvious when results for different growth parameters and yield from plants inoculated with AHL-producing strains SAL-21 and SAL-17 were compared with those of non-AHLproducing strain SAL-12. The role of PGPR in stress tolerance amelioration, plant growth, and yield improvement of several crops is well established (Van Loon, 2007). Plant-beneficial bacteria play a key role in the improvement of crop growth, nutrition, and yields and in sustaining soil productivity with low input of chemical fertilizers under stress (Islam et al., 2016; Yasmeen et al., 2019).

The results of the current study advocate that plant-associated beneficial Aeromonas spp. strains have a significant role in salt stress mitigation and overall plant growth improvement. Moreover, stress-resilient PGPR is the best choice to be used as inoculants under stressful conditions because they can sustain stress and maintain their PGP traits as well. This study indicates the contribution of AHLs in stress tolerance induction, but other plant-growth-promoting factors cannot be ruled out completely. Furthermore, plants can be engineered for AHL production to foster their interaction with beneficial microbes as previously reported for bioengineered plants (Scott et al., 2006). A study in which tomato plants were inoculated with AHL-producing strains and also bioengineered for production of short-chain and long-chain AHLs has concluded that AHLs promote plant growth and confer protection against salt stress (Barriuso et al., 2008). The current study opens future directions for the researchers to study the AHL regulation of microbial process and plant response modulation through induction of stress-responsive genes and signaling pathways.

\section{CONCLUSION}

This study has demonstrated a wide range of AHL production by the halotolerant plant-growth-promoting Aeromonas spp. strains SAL-17 and SAL-21, in which six are unique to the two strains being reported. Exogenous application of purified AHLs significantly increased the root morphology in wheat. Both strains showed the potential to colonize wheat roots and stimulate substantial growth under saline conditions in two different wheat genotypes. The inoculated plants showed higher proline contents, transpiration rate, stomatal conductance, chlorophyll contents, and nitrate reductase activity. The overall growth stimulation may be attributed to a synergistic response of the IAA, ACC-deaminase activity, and AHL production, of which the role of AHLs seems imperative. Future research involving
AHL-deficient mutants, use of synthetic AHLs, and AHLengineered plants will further validate the role of AHLs because, in this study, the comparison of inoculation results for the AHL-producing strains with a strain missing AHL production suggested their significant contribution toward salt stress mitigation and plant growth improvement. A comparison with phenotypically AHL-negative strain derivative using lactonase constructs would result in more direct evidence because the genetic background would be the same. This study concludes that multi-trait, non-pathogenic Aeromonas spp. strains are candidates of choice for the production of inoculum for saline soils. The strains should be used/released in the field only after implementation of biosafety parameters because some aeromonads have clinical significance. The study is of prime importance because 45 million hectares of salt-affected soil direly need an efficient solution for better cropping on a larger scale.

\section{DATA AVAILABILITY STATEMENT}

The data can be found at NCBI [SAL-17 (Accession No. HG763857) and SAL-21 (Accession No. HG763858)].

\section{AUTHOR CONTRIBUTIONS}

MN analyzed the data and wrote the manuscript. AA performed the AHL experiments as part of her MPhil research work. LR conducted the strain characterization and the pot experiments as part of her Ph.D. research. KF performed the confocal studies. SU helped in the AHL screening experiment. MA helped in the pot experiments. AI conceived and supervised the whole study and edited the manuscript. All the authors read and approved the final version of the manuscript.

\section{FUNDING}

This research was carried out by the laboratory support funds provided by the Higher Education Commission.

\section{ACKNOWLEDGMENTS}

The authors are thankful to BioSaline Research Station for help in soil sampling and Dr. Ejaz ul Islam for help in the root analysis on Rhizoscanner.

\section{SUPPLEMENTARY MATERIAL}

The Supplementary Material for this article can be found online at: https://www.frontiersin.org/articles/10.3389/fmicb.2020. 553621/full\#supplementary-material

Supplementary Figure 1 | Phylogenetic relationship of Aeromonas spp. Sal-12, Sal-17, and Sal-21 based on the sequences of 16S rRna along with closely related sequences obtained from GenBank. Boot strap value was 1,000, and 
nucleotide sequence divergence is shown by a bar. The tree was generated in Mega6 using maximum likelihood method.

Supplementary Figure 2 | Grain yield response to proline contents and nitrate reductase activity as a function of bacterial inoculation in two different wheat genotypes grown in both saline and normal soil. Data from all treatments were jointly loaded on the graph to evaluate the overall response.

\section{REFERENCES}

Afridi, M. S., Mahmood, T., Salam, A., Mukhtar, T., Mehmood, S., Ali, J., et al. (2019). Induction of tolerance to salinity in wheat genotypes by plant growth-promoting endophytes: involvement of Acc deaminase and antioxidant enzymes. Plant Physiol. Biochem. 139, 569-577. doi: 10.1016/j.plaphy.2019.03. 041

Ahmad, M., Zahir, Z. A., Asghar, H. N., and Asghar, M. (2011). Inducing salt tolerance in mung bean through co-inoculation with rhizobia and plant-growth-promoting rhizobacteria containing 1-aminocyclopropane-1carboxylate deaminase. Can. J. Microbiol. 57, 578-589. doi: 10.1139/w11044

Ahmad, P., Hashem, A., Abd-Allah, E. F., Alqarawi, A., John, R., Egamberdieva, D., et al. (2015). Role of Trichoderma harzianum in mitigating $\mathrm{NaCl}$ stress in Indian mustard (Brassica juncea L) through antioxidative defense system. Front. Plant Sci. 6:868. doi: 10.3389/fpls.2015.00868

Ali, A., Hameed, S., Imran, A., Iqbal, M., Iqbal, J., and Oresnik, I. J. (2016). Functional characterization of a soybean growth stimulator Bradyrhizobium sp. strain SR-6 showing acyl-homoserine lactone production. FEMS Microbiol. Ecol. 92:fiw115. doi: 10.1093/femsec/fiw115

Ariga, H., Katori, T., Yoshihara, R., Hase, Y., Nozawa, S., Narumi, I., et al. (2013). Arabidopsis sos 1 mutant in a salt-tolerant accession revealed an importance of salt acclimation ability in plant salt tolerance. Plant Signal. Behav. 8:e24779. doi: $10.4161 /$ psb. 24779

Arnon, D. (1949). Measuring chlorophyll and anthocyanin concentration. Plant Physiol. 24, 1-15. doi: 10.1104/pp.24.1.1

Arshadullah, M., Hyder, S. I., Mahmood, I. A., Sultan, T., and Naveed, S. (2017). Mitigation of salt stress in wheat plant (Triticum aestivum) by plant growth promoting rhizobacteria for ACC deaminase. Int. J. Adv. Res. Biol. Sci. 4, 41-46.

Austin, D., McIntosh, D., and Austin, B. (1989). Taxonomy of fish associated Aeromonas spp., with the description of Aeromonas salmonicida subsp. smithia subsp. nov. Syst. Appl. Microbiol. 11, 277-290. doi: 10.1016/S0723-2020(89) 80026-8

Azarmi-Atajan, F., and Sayyari-Zohan, M. H. (2020). Alleviation of salt stress in lettuce (Lactuca sativa L.) by plant growth-promoting rhizobacteria. J. Horticult. Postharvest Res. 3, 67-78.

Babaei, K., Seyed Sharifi, R., Pirzad, A., and Khalilzadeh, R. (2017). Effects of bio fertilizer and nano Zn-Fe oxide on physiological traits, antioxidant enzymes activity and yield of wheat (Triticum aestivum L.) under salinity stress. J. Plant Interact. 12, 381-389. doi: 10.1080/17429145.2017.1371798

Bai, X., Todd, C. D., Desikan, R., Yang, Y., and Hu, X. (2012). N-3-oxo-decanoylL-homoserine-lactone activates auxin-induced adventitious root formation via hydrogen peroxide-and nitric oxide-dependent cyclic GMP signaling in mung bean. Plant Physiol. 158, 725-736. doi: 10.1104/pp.111.185769

Bano, A., and Fatima, M. (2009). Salt tolerance in Zea mays (L.) following inoculation with Rhizobium and Pesudomonas. Biol. Fertil. Soils 45, 405-413. doi: 10.1007/s00374-008-0344-9

Barriuso, J., Ramos Solano, B., Fray, R. G., Cámara, M., Hartmann, A., and Gutiérrez Mañero, F. J. (2008). Transgenic tomato plants alter quorum sensing in plant growth-promoting rhizobacteria. Plant Biotechnol. J. 6, 442-452. doi: 10.1111/j.1467-7652.2008.00331.x

Bates, L. S., Waldren, R. P., and Teare, I. (1973). Rapid determination of free proline for water-stress studies. Plant Soil 39, 205-207. doi: 10.1007/BF0001 8060

Beaz-Hidalgo, R., Alperi, A., Figueras, M., and Romalde, J. (2009). Aeromonas piscicola sp. nov., isolated from diseased fish. Syst. Appl. Microbiol. 32, 471-479. doi: 10.1016/j.syapm.2009.06.004

Bharti, N., and Barnawal, D. (2019). “Amelioration of salinity stress by PGPR: ACC deaminase and ROS scavenging enzymes activity," in PGPR Amelioration in
The graph shows the quadratic relationship of grain yield to plant proline and nitrate reductase activity, with significantly high $R^{2}$ values.

Supplementary Table 1 | Occurrence and functional annotation of acyl homoserine lactones in spent culture supernatant of Aeromonas spp. reported in literature.

Sustainable Agriculture, eds A. K. Singh, A. Kumar, and P. K. Singh (Cambridge: Woodhead Publishing), 85-106. doi: 10.1016/B978-0-12-815879-1.00005-7

Bharti, N., Yadav, D., Barnawal, D., Maji, D., and Kalra, A. (2013). Exiguobacterium oxidotolerans, a halotolerant plant growth promoting rhizobacteria, improves yield and content of secondary metabolites in Bacopa monnieri (L.) Pennell under primary and secondary salt stress. World J. Microbiol. Biotechnol. 29, 379-387. doi: 10.1007/s11274-012-1192-1

Bi, X.-D., Zhou, W.-L., Xing, K.-Z., and Tang, X.-X. (2012). Effects of AHLs (Nhexanoyl-DL-homoserine lactone, C 6-HSL) on growth and antioxidant defense system of Chlorella vulgaris. Mar. Environ. Sci. 31, 897-900.

Buckley, T. N., and Mott, K. A. (2013). Modelling stomatal conductance in response to environmental factors. Plant Cell Environ. 36, 1691-1699. doi: $10.1111 /$ pce. 12140

Bui, E. (2013). Soil salinity: a neglected factor in plant ecology and biogeography. J. Arid Environ. 92, 14-25. doi: 10.1016/j.jaridenv.2012.12.014

Chamizo-Ampudia, A., Sanz-Luque, E., Llamas, A., Galvan, A., and Fernandez, E. (2017). Nitrate reductase regulates plant nitric oxide homeostasis. Trends Plant Sci. 22, 163-174. doi: 10.1016/j.tplants.2016.12.001

Chapalain, A., Vial, L., Laprade, N., Dekimpe, V., Perreault, J., and Déziel, E. (2013). Identification of quorum sensing-controlled genes in Burkholderia ambifaria. Microbiol. Open 2, 226-242. doi: 10.1002/mbo3.67

Cheng, F., Ma, A., Zhuang, G., and Fray, R. G. (2018). Exogenous N-acylhomoserine lactones enhance the expression of flagella of Pseudomonas syringae and activate defence responses in plants. Mol. Plant Pathol. 19, 104-115. doi: 10.1111/mpp.12502

Chibani, H. R., Bouznad, A., Bellahcene, M., and Djibaoui, R. (2016). Screening and characterization of plant growth promoting traits of phosphate solubilizing bacteria isolated from wheat rhizosphere of Algerian saline soil. Malaysian J. Microbiol. 13, 124-131. doi: 10.21161/mjm.91916

Chin-A-Woeng, T. F., van den Broek, D., de Voer, G., van der Drift, K. M., Tuinman, S., Thomas-Oates, J. E., et al. (2001). Phenazine-1carboxamide production in the biocontrol strain Pseudomonas chlororaphis PCL1391 is regulated by multiple factors secreted into the growth medium. Mol. Plant Microbe Interact. 14, 969-979. doi: 10.1094/MPMI.2001.14. 8.969

de Wit, R., Mostajir, B., Troussellier, M., and Do Chi, T. (2011). "Environmental management and sustainable use of coastal lagoons ecosystems," in Lagoons: Biology Management and Environmental Impact Series, ed. A. G. Friedman (Hauppauge, NY: Nova publishers), 333-350.

del Carmen Orozco-Mosqueda, M., Glick, B. R., and Santoyo, G. (2020). ACC deaminase in plant growth-promoting bacteria (PGPB): an efficient mechanism to counter salt stress in crops. Microbiol. Res. 235:126439. doi: 10.1016/j.micres. 2020.126439

Ding, L., Cao, J., Duan, Y., Li, J., Yang, Y., Yang, G., et al. (2016). Retracted: proteomic and physiological responses of Arabidopsis thaliana exposed to salinity stress and N-acyl-homoserine lactone. Physiol. Plant. 158, 414-434. doi: $10.1111 /$ ppl.12476

Dodd, I. C., and Pérez-Alfocea, F. (2012). Microbial amelioration of crop salinity stress. J. Exp. Bot. 63, 3415-3428. doi: 10.1093/jxb/ers033

Dou, Y., Jiang, Z., Zhang, W., Gao, J., Jiang, M., Shi, X., et al. (2017). Effects of AHLs on PSII photochemistry activity and photosynthesis crucial enzymes of Chlorella vulgaris. Acta Hydrobiol. Sin. 41, 629-636.

Downie, J. A., Hombrecher, G. Q. S. Ma, Knight, C. D., Wells, B., and Johnston, A. W. B. (1983). Cloned nodulation genes of Rhizobium leguminosarum determine host range specicity. Mol. Gen. Genet. 190, 359-365. doi: 10.1007/ BF00331059

Egamberdieva, D., Renella, G., Wirth, S., and Islam, R. (2010). Secondary salinity effects on soil microbial biomass. Biol. Fertil. Soils 46, 445-449. doi: 10.1007/ s00374-010-0452-1 
Esteve, C., Gutiérrez, M. C., and Ventosa, A. (1995). Aeromonas encheleia sp. nov., isolated from European eels. Int. J. Syst. Evol. Microbiol. 45, 462-466. doi: 10.1099/00207713-45-3-462

Esteve, C., Valera, L., Gutierrez, C., and Ventosa, A. (2003). Taxonomic study of sucrose-positive Aeromonas jandaei-like isolates from faeces, water and eels: emendation of A. jandaei Carnahan et al. 1992. Int. J. Syst. Evol. Microbiol. 53, 1411-1419. doi: 10.1099/ijs.0.02504-0

FAO (2020). Salt-Affected Soils [Online]. Rome: FAO.

Garcia de la Garma, J., Fernandez-Garcia, N., Bardisi, E., Pallol, B., Asensio-Rubio, J. S., Bru, R., et al. (2015). New insights into plant salt acclimation: the roles of vesicle trafficking and reactive oxygen species signalling in mitochondria and the endomembrane system. New Phytol. 205, 216-239. doi: 10.1111/nph.12997

González, J. E., and Marketon, M. M. (2003). Quorum sensing in nitrogen-fixing rhizobia. Microbiol. Mol. Biol. Rev. 67, 574-592. doi: 10.1128/MMBR.67.4.574592.2003

Götz, C., Fekete, A., Gebefuegi, I., Forczek, S. T., Fuksová, K., Li, X., et al. (2007). Uptake, degradation and chiral discrimination of N-acyl-D/L-homoserine lactones by barley (Hordeum vulgare) and yam bean (Pachyrhizus erosus) plants. Anal. Bioanal. Chem. 389, 1447-1457. doi: 10.1007/s00216-007-1579-2

Gupta, B., and Huang, B. (2014). Mechanism of salinity tolerance in plants: physiological, biochemical, and molecular characterization. Int. J. Genomics 2014, 701596. doi: 10.1155/2014/701596

Han, Q.-Q., Lü, X.-P., Bai, J.-P., Qiao, Y., Paré, P. W., Wang, S.-M., et al. (2014). Beneficial soil bacterium Bacillus subtilis (GB03) augments salt tolerance of white clover. Front. Plant Sci. 5:525. doi: 10.3389/fpls.2014.00525

Han, S., Li, D., Trost, E., Mayer, K. F., Vlot, A. C., Heller, W., et al. (2016). Systemic responses of barley to the 3-hydroxy-decanoyl-homoserine lactone producing plant beneficial endophyte Acidovorax radicis N35. Front. Plant Sci. 7:1868. doi: $10.3389 /$ fpls. 2016.01868

Hanif, M. K., Malik, K. A., Hameed, S., Saddique, M. J., Ayesha, Fatima, K., et al. (2020). Growth stimulatory effect of AHL producing Serratia spp. from potato on homologous and non-homologous host plants. Microbiol. Res. 238, 126506. doi: 10.1016/j.micres.2020.126506

Hashem, A., Abd_Allah, E. F., Alqarawi, A. A., Aldubise, A., and Egamberdieva, D. (2015). Arbuscular mycorrhizal fungi enhances salinity tolerance of Panicum turgidum Forssk by altering photosynthetic and antioxidant pathways. J. Plant Interact. 10, 230-242. doi: 10.1080/17429145.2015.1052025

Hickman-Brenner, F., MacDonald, K., Steigerwalt, A., Fanning, G., Brenner, D. J., and Farmer, J. D. (1987). Aeromonas veronii, a new ornithine decarboxylasepositive species that may cause diarrhea. J. Clin. Microbiol. 25, 900-906. doi: 10.1128/JCM.25.5.900-906.1987

Hu, X., Bai, X., Todd, C., Desikan, R., and Yang, Y. (2012). N-3-oxo-decanoylL-homoserine-lactone activates auxin-induced adventitious root formation via $\mathrm{H} 2 \mathrm{O} 2$-and Nitric oxide-dependent Cyclic GMP Signalling in Mung Bean. Plant Physiol. 158, 725-736.

Hu, Z., Shao, S., Zheng, C., Sun, Z., Shi, J., Yu, J., et al. (2018). Induction of systemic resistance in tomato against Botrytis cinerea by N-decanoylhomoserine lactone via jasmonic acid signaling. Planta 247, 1217-1227. doi: 10.1104/pp.111.185769

Hu, Z., Sun, Z., Ma, Q., Yang, X., Feng, S., Shao, S., et al. (2020). N-decanoylhomoserine lactone alleviates elevated CO2-induced defense suppression to Botrytis cinerea in tomato. Sci. Horticult. 238:109353. doi: 10.1016/j.scienta. 2020.109353

Huys, G., Kámpfer, P., Altwegg, M., Kersters, I., Lamb, A., Coopman, R., et al. (1997). Aeromonas popoffii sp. nov., a mesophilic bacterium isolated from drinking water production plants and reservoirs. Int. J. Syst. Evol. Microbiol. 47, 1165-1171. doi: 10.1099/00207713-47-4-1165

Imran, A., Saadalla, M. J. A., Khan, S.-U., Mirza, M. S., Malik, K. A., and Hafeez, F. Y. (2014). Ochrobactrum sp. Pv2Z2 exhibits multiple traits of plant growth promotion, biodegradation and $\mathrm{N}$-acyl-homoserine-lactone quorum sensing. Ann. Microbiol. 64, 1797-1806. doi: 10.1007/s13213-014-0824-0

Inbar, J., and Chet, I. (1991). Evidence that chitinase produced by Aeromonas caviae is involved in the biological control of soil-borne plant pathogens by this bacterium. Soil Biol. Biochem. 23, 973-978. doi: 10.1016/0038-0717(91)90178$\mathrm{M}$

Iqbal, N., Umar, S., Khan, N. A., and Khan, M. I. R. (2014). A new perspective of phytohormones in salinity tolerance: regulation of proline metabolism. Environ. Exp. Bot. 100, 34-42. doi: 10.1016/j.envexpbot.2013.12.006
Islam, F., Yasmeen, T., Arif, M. S., Ali, S., Ali, B., Hameed, S., et al. (2016). Plant growth promoting bacteria confer salt tolerance in Vigna radiata by up-regulating antioxidant defense and biological soil fertility. Plant Growth Regul. 80, 23-36. doi: 10.1007/s10725-015-0142-y

Ismail, A., Takeda, S., and Nick, P. (2014). Life and death under salt stress: same players, different timing? J. Exp. Bot. 65, 2963-2979. doi: 10.1093/jxb/eru159

Jha, Y., and Subramanian, R. (2014). PGPR regulate caspase-like activity, programmed cell death, and antioxidant enzyme activity in paddy under salinity. Physiol. Mol. Biol. Plants 20, 201-207. doi: 10.1007/s12298-014-0224-8

Ji, J., Yuan, D., Jin, C., Wang, G., Li, X., and Guan, C. (2020). Enhancement of growth and salt tolerance of rice seedlings (Oryza sativa L.) by regulating ethylene production with a novel halotolerant PGPR strain Glutamicibacter sp. YD01 containing ACC deaminase activity. Acta Physiol. Plant. 42, 1-17. doi: $10.1007 /$ s1 1738-020-3034-3

Joseph, C. M., and Phillips, D. A. (2003). Metabolites from soil bacteria affect plant water relations. Plant Physiol. Biochem. 41, 189-192. doi: 10.1016/S09819428(02)00021-9

Jukes, T., and Cantor, C. (1969). "Evolution of protein molecules," in A Mmalian Protein Metabolism, ed. H. N. Munro (New York, NY: Academic Press), 21-132. doi: 10.1016/B978-1-4832-3211-9.50009-7

Koutsoudis, M. D., Tsaltas, D., Minogue, T. D., and von Bodman, S. B. (2006). Quorum-sensing regulation governs bacterial adhesion, biofilm development, and host colonization in Pantoea stewartii subspecies stewartii. Proc. Natl. Acad. Sci. U.S.A. 103, 5983-5988. doi: 10.1073/pnas.0509860103

Kronzucker, H. J., and Britto, D. T. (2011). Sodium transport in plants: a critical review. New Phytol. 189, 54-81. doi: 10.1111/j.1469-8137.2010.03540.x

Kumar, S., Stecher, G., and Tamura, K. (2016). MEGA7: molecular evolutionary genetics analysis version 7.0 for bigger datasets. Mol. Biol. Evol. 33, 1870-1874. doi: 10.1093/molbev/msw054

Kumari, S., Vaishnav, A., Jain, S., Varma, A., and Choudhary, D. K. (2015). Bacterial-mediated induction of systemic tolerance to salinity with expression of stress alleviating enzymes in soybean (Glycine max L. Merrill). J. Plant Growth Regul. 34, 558-573. doi: 10.1007/s00344-015-9490-0

Kundu, B., Nehra, K., Yadav, R., and Tomar, M. (2009). Biodiversity of phosphate solubilizing bacteria in rhizosphere of chickpea, mustard and wheat grown in different regions of Haryana. Indian J. Microbiol. 49, 120-127. doi: 10.1007/ s12088-009-0016-y

Li, T., Cui, F., Bai, F., Zhao, G., and Li, J. (2016). Involvement of acylated homoserine lactones (AHLs) of Aeromonas sobria in spoilage of refrigerated turbot (Scophthalmus maximus L.). Sensors 16:1083. doi: 10.3390/s16071083

Li, Y., George, J. E., McCarty, C. L., and Wendelken, S. C. (2006). Compliance analysis of phenylurea and related compounds in drinking water by liquid chromatography/electrospray ionization/mass spectrometry coupled with solid-phase extraction. J. Chromatogr. A 1134, 170-176. doi: 10.1016/j.chroma. 2006.08.081

Lim, Y.-L., Ee, R., Yin, W.-F., and Chan, K.-G. (2014). Quorum sensing activity of Aeromonas caviae strain YL12, a bacterium isolated from compost. Sensors 14, 7026-7040. doi: 10.3390/s140407026

Liu, X., Jia, J., Atkinson, S., Cámara, M., Gao, K., Li, H., et al. (2010). Biocontrol potential of an endophytic Serratia sp. G3 and its mode of action. World J. Microbiol. Biotechnol. 26, 1465-1471. doi: 10.1007/s11274-010-0321-y

Llamas, I., Quesada, E., Martínez-Cánovas, M. J., Gronquist, M., Eberhard, A., and Gonzalez, J. E. (2005). Quorum sensing in halophilic bacteria: detection of $\mathrm{N}$-acyl-homoserine lactones in the exopolysaccharide-producing species of Halomonas. Extremophiles 9, 333-341. doi: 10.1007/s00792-005-0448-1

Lugtenberg, B., and Kamilova, F. (2009). Plant-growth-promoting rhizobacteria. Annu. Rev. Microbiol. 63, 541-556. doi: 10.1146/annurev.micro.62.081307. 162918

Lv, S., Jiang, P., Chen, X., Fan, P., Wang, X., and Li, Y. (2012). Multiple compartmentalization of sodium conferred salt tolerance in Salicornia europaea. Plant Physiol. Biochem. 51, 47-52. doi: 10.1016/j.plaphy.2011. 10.015

Martínez-Murcia, A. J., Soler, L., Saavedra, M. J., Chacón, M. R., Guarro, J., Stackebrandt, E., et al. (2005). Phenotypic, genotypic, and phylogenetic discrepancies to differentiate Aeromonas salmonicida from Aeromonas bestiarum. Int. Microbiol. 8, 259-269.

Mathesius, U., Mulders, S., Gao, M., Teplitski, M., Caetano-Anollés, G., Rolfe, B. G., et al. (2003). Extensive and specific responses of a eukaryote to bacterial 
quorum-sensing signals. Proc. Natl. Acad. Sci. U.S.A. 100, 1444-1449. doi: $10.1073 /$ pnas. 262672599

McClean, K. H., Winson, M. K., Fish, L., Taylor, A., Chhabra, S. R., Camara, M., et al. (1997). Quorum sensing and Chromobacterium violaceum: exploitation of violacein production and inhibition for the detection of $\mathrm{N}$-acylhomoserine lactones. Microbiology 143, 3703-3711. doi: 10.1099/00221287-143-12-3703

Mehnaz, S., Mirza, M. S., Haurat, J., Bally, R., Normand, P., Bano, A., et al. (2001). Isolation and 16S rRNA sequence analysis of the beneficial bacteria from the rhizosphere of rice. Can. J. Microbiol. 47, 110-117. doi: 10.1139/w00-132

Miñana-Galbis, D., Farfan, M., Fuste, M. C., and Loren, J. G. (2004). Aeromonas molluscorum sp. nov., isolated from bivalve molluscs. Int. J. Syst. Evol. Microbiol. 54, 2073-2078. doi: 10.1099/ijs.0.63202-0

Miñana-Galbis, D., Farfan, M., Fusté, M. C., and Lorén, J. G. (2007). Aeromonas bivalvium sp. nov., isolated from bivalve molluscs. Int. J. Syst. Evol. Microbiol. 57, 582-587. doi: 10.1099/ijs.0.64497-0

Miñana-Galbis, D., Farfán, M., Lorén, J. G., and Fusté, M. C. (2002). Biochemical identification and numerical taxonomy of Aeromonas spp. isolated from environmental and clinical samples in Spain. J. Appl. Microbiol. 93, 420-430. doi: 10.1046/j.1365-2672.2002.01711.x

Müller, H. (2006). Novel Concepts in Biological Plant Protection on the Basis of the Biological Control Agent Serratia Plymuthica HRO-C48. Doctoral dissertation. Germany: University of Rostock.

Müller, H., Westendorf, C., Leitner, E., Chernin, L., Riedel, K., Schmidt, S., et al. (2009). Quorum-sensing effects in the antagonistic rhizosphere bacterium Serratia plymuthica HRO-C48. FEMS Microbiol. Ecol. 67, 468-478. doi: 10. 1111/j.1574-6941.2008.00635.x

Munns, R., James, R. A., Xu, B., Athman, A., Conn, S. J., Jordans, C., et al. (2012). Wheat grain yield on saline soils is improved by an ancestral $\mathrm{Na}+$ transporter gene. Nat. Biotechnol. 30:360. doi: 10.1038/nbt.2120

Nadeem, S. M., Zahir, Z. A., Naveed, M., and Arshad, M. (2007). Preliminary investigations on inducing salt tolerance in maize through inoculation with rhizobacteria containing ACC deaminase activity. Can. J. Microbiol. 53, 11411149. doi: 10.1139/W07-081

Naqqash, T., Imran, A., Hameed, S., Shahid, M., Majeed, A., Iqbal, M. J., et al. (2020). First Report of diazotrophic Brevundimonas spp. as growth enhancer and root colonizer of potato. Sci. Rep. 10, 1-14. doi: 10.1038/s41598-02069782-6

Ortíz-Castro, R., Martínez-Trujillo, M., and López-Bucio, J. (2008). N-acyl-Lhomoserine lactones: a class of bacterial quorum-sensing signals alter postembryonic root development in Arabidopsis thaliana. Plant Cell Environ. 31, 1497-1509. doi: 10.1111/j.1365-3040.2008.01863.x

Pan, J., Peng, F., Xue, X., You, Q., Zhang, W., Wang, T., et al. (2019). The growth promotion of two salt-tolerant plant groups with PGPR inoculation: a meta-analysis. Sustainability 11:378. doi: 10.3390/su11020378

Pan, Q.-N., Geng, C.-C., Li, D.-D., Xu, S.-W., Mao, D.-D., Umbreen, S., et al. (2019). Nitrate reductase-mediated nitric oxide regulates the leaf shape in Arabidopsis by mediating the homeostasis of reactive oxygen species. Int. J. Mol. Sci. 20:2235. doi: 10.3390/ijms20092235

Pang, Y., Liu, X., Ma, Y., Chernin, L., Berg, G., and Gao, K. (2009). Induction of systemic resistance, root colonisation and biocontrol activities of the rhizospheric strain of Serratia plymuthica are dependent on $\mathrm{N}$-acyl homoserine lactones. Eur. J. Plant Pathol. 124, 261-268. doi: 10.1007/s10658-008-9411-1

Papenfort, K., and Bassler, B. L. (2016). Quorum sensing signal-response systems in Gram-negative bacteria. Nat. Rev. Microbiol. 14, 576. doi: 10.1038/nrmicro. 2016.89

Popoff, M., and VéEron, M. (1976). A taxonomic study of the Aeromonas hydrophila-Aeromonas punctata group. Microbiology 94, 11-22. doi: 10.1099/ 00221287-94-1-11

Príncipe, A., Alvarez, F., Castro, M. G., Zachi, L., Fischer, S. E., Mori, G. B., et al. (2007). Biocontrol and PGPR features in native strains isolated from saline soils of Argentina. Curr. Microbiol. 55, 314-322. doi: 10.1007/s00284-006-0654-9

Rajendran, R., Sundaram, S. K., and Maheswari, K. U. (2011). Aerobic biodecolorization of mixture of azo dye containing textile effluent using adapted microbial strains. J. Environ. Sci. Technol. 4, 568-578. doi: 10.3923/jest.2011. 568.578

Rajput, L., Imran, A., Mubeen, F., and Hafeez, F. Y. (2018). Wheat (Triticum aestivum L.) growth promotion by halo-tolerant PGPR-consortium. Soil Environ. 37, 178-189.
Rankl, S., Gunsé, B., Sieper, T., Schmid, C., Poschenrieder, C., and Schröder, P. (2016). Microbial homoserine lactones (AHLs) are effectors of root morphological changes in barley. Plant Sci. 253, 130-140. doi: 10.1016/j. plantsci.2016.09.014

Robin, P. (1979). Study of some conditions for extracting nitrate reductase from the roots and leaves of corn seedlings. Physiol. Vég. 17, 55-66.

Ryu, C.-M., Choi, H. K., Lee, C.-H., Murphy, J. F., Lee, J.-K., and Kloepper, J. W. (2013). Modulation of quorum sensing in acylhomoserine lactone-producing or-degrading tobacco plants leads to alteration of induced systemic resistance elicited by the rhizobacterium Serratia marcescens 90-166. Plant Pathol. J. 29, 182-192. doi: 10.5423/PPJ.SI.11.2012.0173

Safni, I., and Antastia, W. (2018). In vitro antagonism of five rhizobacterial species against athelia rolfsii collar rot disease in soybean. Open Agric. 3, 264-272. doi: 10.1515/opag-2018-0028

Saleem, K., Arshad, H. M. A., Shokat, S., and Atta, B. M. (2015). Appraisal of wheat germplasm for adult plant resistance against stripe rust. J. Plant Protect. Res. 55, 405-415. doi: 10.1515/jppr-2015-0055

Sánchez-Matamoros, R. C., Gil-Serrano, A. M., Espuny, M. R., Ollero, F. J., Megías, M., and Rodríguez-Carvajal, M. A. (2018). Structure of surface polysaccharides from Aeromonas sp. AMG272, a plant-growth promoting rhizobacterium isolated from rice rhizosphere. Carbohydr. Res. 462, 1-6. doi: 10.1016/j.carres. 2018.03.012

Sarkar, A., Ghosh, P. K., Pramanik, K., Mitra, S., Soren, T., Pandey, S., et al. (2018). A halotolerant Enterobacter sp. displaying ACC deaminase activity promotes rice seedling growth under salt stress. Res. Microbiol. 169, 20-32. doi: 10.1016/j.resmic.2017.08.005

Schenk, S. T., and Schikora, A. (2015). AHL-priming functions via oxylipin and salicylic acid. Front. Plant Sci. 5:784. doi: 10.3389/fpls.2014.00784

Schikora, A., Schenk, S. T., and Hartmann, A. (2016). Beneficial effects of bacteria-plant communication based on quorum sensing molecules of theNacyl homoserine lactone group. Plant Mol. Biol. 90, 605-612. doi: 10.1007/ s11103-016-0457-8

Schuhegger, R., Ihring, A., Gantner, S., et al. (2006). Induction of systemic resistance in tomato by $N$-acyl-l-homoserine lactone-producing rhizosphere bacteria. Plant Cell Environ. 29, 909-918. doi: 10.1111/j.1365-3040.2005.01471. $\mathrm{x}$

Scott, R. A., Weil, J., Le, P. T., Williams, P., Fray, R. G., von Bodman, S. B., et al. (2006). Long-and short-chain plant-produced bacterial N-acyl-homoserine lactones become components of phyllosphere, rhizosphere, and soil. Mol. Plant Microbe Interact. 19, 227-239. doi: 10.1094/MPMI-19-0227

Sieper, T., Forczek, S., Matucha, M., Krämer, P., Hartmann, A., and Schröder, P. (2014). N-acyl-homoserine lactone uptake and systemic transport in barley rest upon active parts of the plant. New Phytol. 201, 545-555. doi: 10.1111/nph. 12519

Singh, R. P., and Jha, P. N. (2016a). A halotolerant bacterium Bacillus licheniformis HSW-16 augments induced systemic tolerance to salt stress in wheat plant (Triticum aestivum). Front. Plant Sci. 7:1890. doi: 10.3389/fpls.2016.01890

Singh, R. P., and Jha, P. N. (2016b). The multifarious PGPR Serratia marcescens CDP-13 augments induced systemic resistance and enhanced salinity tolerance of wheat (Triticum aestivum L.). PLoS One 11:e0155026. doi: 10.1371/journal. pone. 0155026

Sivakumar, K., Scarascia, G., Zaouri, N., Wang, T., Kaksonen, A. H., and Hong, P.Y. (2019). Salinity-mediated increment in sulfate reduction, biofilm formation, and quorum sensing: a potential connection between quorum sensing and sulfate reduction? Front. Microbiol. 10:188. doi: 10.3389/fmicb.2019.00188

Smibert, R. M., and Krieg, N. R. (1994). "Phenotypic characterization," in Methods for General and Molecular Bacteriology, eds P. Gerhardt, R. G. E. Murray, W. A. Wood, and N. R. Krieg (Washington DC: American Society for Microbiology), 607-654.

Sneha, S., Rishi, A., Dadhich, A., and Chandra, S. (2013). Effect of salinity on seed germination, accumulation of proline and free amino acid in Pennisetum glaucum (L.) R. Br. Pakistan J. Biol. Sci. 16, 877-881. doi: 10.3923/pjbs.2013. 877.881

Steidle, A., Allesen-Holm, M., Riedel, K., Berg, G., Givskov, M., Molin, S., et al. (2002). Identification and characterization of an $\mathrm{N}$-acylhomoserine lactone-dependent quorum-sensing system in Pseudomonas putida strain IsoF. Appl. Environ. Microbiol. 68, 6371-6382. doi: 10.1128/AEM.68.12.6371-6382. 2002 
Steidle, A., Sigl, K., Schuhegger, R., Ihring, A., Schmid, M., Gantner, S., et al. (2001). Visualization of $\mathrm{N}$-acylhomoserine lactone-mediated cell-cell communication between bacteria colonizing the tomato rhizosphere. Appl. Environ. Microbiol. 67, 5761-5770. doi: 10.1128/AEM.67.12.5761-5770.2001

Sun, H., Li, J., Song, W., Tao, J., Huang, S., Chen, S., et al. (2015). Nitric oxide generated by nitrate reductase increases nitrogen uptake capacity by inducing lateral root formation and inorganic nitrogen uptake under partial nitrate nutrition in rice. J. Exp. Bot. 66, 2449-2459. doi: 10.1093/jxb/erv030

Sutherland, I. W. (2001). Biofilm exopolysaccharides: a strong and sticky framework. Microbiology 147, 3-9. doi: 10.1099/00221287-147-1-3

Tahrioui, A., Schwab, M., Quesada, E., and Llamas, I. (2013). Quorum sensing in some representative species of Halomonadaceae. Life 3, 260-275. doi: 10.3390/ life 3010260

Torres, M., Dessaux, Y., and Llamas, I. (2019). Saline environments as a source of potential quorum sensing disruptors to control bacterial infections: a review. Mar. Drugs 17:191. doi: 10.3390/md17030191

Upadhyay, S. K., Singh, J. S., Saxena, A. K., and Singh, D. P. (2012). Impact of PGPR inoculation on growth and antioxidant status of wheat under saline conditions. Plant Biol. 14, 605-611. doi: 10.1111/j.1438-8677.2011.00533.x

Upadhyaya, H., Sahoo, L., and Panda, S. K. (2013). "Molecular physiology of osmotic stress in plants," in Molecular Stress Physiology of Plants, eds G. R. Rout and A. B. Das (India: Springer), 179-192. doi: 10.1007/978-81-322-0807-5_7

Van Loon, L. (2007). "Plant responses to plant growth-promoting rhizobacteria," in New Perspectives and Approaches in Plant Growth-Promoting Rhizobacteria Research, eds P. A. H. M. Bakker, J. M. Raaijmakers, G. Bloemberg, M. Höfte, P. Lemanceau, and B. M. Cooke (Dordrecht: Springer), 243-254. doi: 10.1007/ 978-1-4020-6776-1_2

Vazquez, M. M., Casalongué, C. A., and París, R. (2019). Nitrate reductase mediates nitric oxide-dependent gravitropic response in Arabidopsis thaliana roots. Plant Signal. Behav. 14:e1578631. doi: 10.1080/15592324.2019.1578631

von Rad, U., Klein, I., Dobrev, P. I., Kottova, J., Zazimalova, E., Fekete, A., et al. (2008). Response of Arabidopsis thaliana to N-hexanoyl-DL-homoserinelactone, a bacterial quorum sensing molecule produced in the rhizosphere. Planta 229, 73-85. doi: 10.1007/s00425-008-0811-4

Wang, Y.-J., and Leadbetter, J. R. (2005). Rapid acyl-homoserine lactone quorum signal biodegradation in diverse soils. Appl. Environ. Microbiol. 71, 1291-1299. doi: 10.1128/AEM.71.3.1291-1299.2005

Wani, S. H., Kumar, V., Khare, T., Guddimalli, R., Parveda, M., Solymosi, K., et al. (2020). Engineering salinity tolerance inplants: progress andprospects. Planta 251:76. doi: 10.1007/s00425-020-03366-6

Wei, H.-L., and Zhang, L.-Q. (2006). Quorum-sensing system influences root colonization and biological control ability in Pseudomonas fluorescens 2P24. Antonie Van Leeuwenhoek 89, 267-280. doi: 10.1007/s10482-0059028-8
Wood, D. W., Gong, F., Daykin, M. M., Williams, P., and Pierson, L. (1997). Nacyl-homoserine lactone-mediated regulation of phenazine gene expression by Pseudomonas aureofaciens 30-84 in the wheat rhizosphere. J. Bacteriol. 179, 7663-7670. doi: 10.1128/JB.179.24.7663-7670.1997

Wu, Z., Peng, Y., Guo, L., and Li, C. (2014). Root colonization of encapsulated Klebsiella oxytoca Rs- 5 on cotton plants and its promoting growth performance under salinity stress. Eur. J. Soil Biol. 60, 81-87. doi: 10.1016/j.ejsobi.2013.11. 008

Yang, J., Kloepper, J. W., and Ryu, C.-M. (2009). Rhizosphere bacteria help plants tolerate abiotic stress. Trends Plant Sci. 14, 1-4. doi: 10.1016/j.tplants.2008.10. 004

Yasmeen, T., Tariq, M., Iqbal, S., Arif, M. S., Riaz, M., Shahzad, S. M., et al. (2019). "Ameliorative capability of plant growth promoting Rhizobacteria (PGPR) and Arbuscular Mycorrhizal Fungi (AMF) against salt stress in plant," in Plant Abiotic Stress Tolerance, eds A. N. Yadav, A. A. Rastegari, N. Yadav, and D. Kour (Cham: Springer), 409-448. doi: 10.1007/978-3-030-06118-0_17

Yin, M., Ma, Z., Cai, Z., Lin, G., and Zhou, J. (2015). Genome sequence analysis reveals evidence of quorum-sensing genes present in Aeromonas hydrophila strain KOR1, isolated from a mangrove plant (Kandelia obovata). Genome Announc. 3:e01461-15. doi: 10.1128/genomeA.014 61-15

Zarkani, A. A., Stein, E., Röhrich, C. R., Schikora, M., Evguenieva-Hackenberg, E., Degenkolb, T., et al. (2013). Homoserine lactones influence the reaction of plants to rhizobia. Int. J. Mol. Sci. 14, 17122-17146. doi: 10.3390/ijms14081 7122

Zhao, Q., Zhang, C., Jia, Z., Huang, Y., Li, H., and Song, S. (2015). Involvement of calmodulin in regulation of primary root elongation by $\mathrm{N}$-3-oxo-hexanoyl homoserine lactone in Arabidopsis thaliana. Front. Plant Sci. 5:807. doi: 10. 3389/fpls.2014.00807

Zhou, H., Yao, F., Roberts, D. P., and Lessie, T. G. (2003). AHL-deficient mutants of Burkholderia ambifaria BC-F have decreased antifungal activity. Curr. Microbiol. 47, 0174-0179. doi: 10.1007/s00284-002-3926-Z

Conflict of Interest: The authors declare that the research was conducted in the absence of any commercial or financial relationships that could be construed as a potential conflict of interest.

Copyright (C) 2020 Nawaz, Arshad, Rajput, Fatima, Ullah, Ahmad and Imran. This is an open-access article distributed under the terms of the Creative Commons Attribution License (CC BY). The use, distribution or reproduction in other forums is permitted, provided the original author(s) and the copyright owner(s) are credited and that the original publication in this journal is cited, in accordance with accepted academic practice. No use, distribution or reproduction is permitted which does not comply with these terms. 